IZA DP No. 7593

Multidimensional Targeting and Evaluation:

A General Framework with an Application to a Poverty Program in Bangladesh

Virginia Robano

Stephen C. Smith

August 2013 


\title{
Multidimensional Targeting and Evaluation: A General Framework with an Application to a Poverty Program in Bangladesh
}

\author{
Virginia Robano \\ OECD and George Washington University, IIEP \\ Stephen C. Smith \\ George Washington University and IZA
}

Discussion Paper No. 7593

August 2013

\author{
IZA \\ P.O. Box 7240 \\ 53072 Bonn \\ Germany \\ Phone: +49-228-3894-0 \\ Fax: +49-228-3894-180 \\ E-mail: iza@iza.org
}

\begin{abstract}
Any opinions expressed here are those of the author(s) and not those of IZA. Research published in this series may include views on policy, but the institute itself takes no institutional policy positions. The IZA research network is committed to the IZA Guiding Principles of Research Integrity.

The Institute for the Study of Labor (IZA) in Bonn is a local and virtual international research center and a place of communication between science, politics and business. IZA is an independent nonprofit organization supported by Deutsche Post Foundation. The center is associated with the University of Bonn and offers a stimulating research environment through its international network, workshops and conferences, data service, project support, research visits and doctoral program. IZA engages in (i) original and internationally competitive research in all fields of labor economics, (ii) development of policy concepts, and (iii) dissemination of research results and concepts to the interested public.
\end{abstract}

IZA Discussion Papers often represent preliminary work and are circulated to encourage discussion. Citation of such a paper should account for its provisional character. A revised version may be available directly from the author. 


\title{
ABSTRACT
}

\section{Multidimensional Targeting and Evaluation: A General Framework with an Application to a Poverty Program in Bangladesh*}

\begin{abstract}
Many poverty, safety net, training, and other social programs utilize multiple screening criteria to determine eligibility. We apply recent advances in multidimensional measurement analysis to develop a straightforward method for summarizing changes in groups of eligibility (screening) indicators, which have appropriate properties. We show how this impact can differ across participants with differing numbers of initial deprivations. We also examine impacts on other specially designed multidimensional poverty measures (and their components) that address key participant deficits. We apply our methods to a BRAC ultrapoverty program in Bangladesh, and find that our measures of multidimensional poverty have fallen significantly for participants. This improvement is most associated with better food security and with acquisition of basic assets (though this does not mean that the cause of poverty reduction was program activities focused directly on these deficits). In general, we find that the BRAC program had a greater impact on reducing multidimensional poverty for those with a larger initial number of deprivations. We also showed how evaluation evidence can be used to help improve the selection of eligibility characteristics of potential participants.
\end{abstract}

JEL Classification: $\quad 015,132$

Keywords: poverty, multidimensional poverty, poverty alleviation strategies, BRAC, microfinance institutions, ultra-poverty, ultra-poor, CFPR/TUP, Bangladesh, difference-in-difference, impact assessment, program evaluation, counterfactual targeting, assignment errors

Corresponding author:

Stephen C. Smith

Department of Economics

GWU

2115 G St. NW

Washington DC 20052

USA

E-mail: ssmith@gwu.edu

\footnotetext{
* We thank BRAC's Research and Evaluation Division (RED), especially Munshi Sulaiman, for providing us with the panel data used in this paper, helping with many clarifications on the data, and facilitating our field visits. We also thank Jim Berry, Tony Castleman, Shahe Emran, James Foster, Ravi Kanbur, Luis Felipe López Calva, Erik Thorbecke, Chen Xi, and participants at the Symposium on Ultra-Poverty (GWU, March 22-23, 2012), the Nordic Conference in Development Economics (Univ. of Gothenburg, Sweden June 18-19, 2012), the Sixteenth IAFEP Conference (Rutgers University, July 12-14, 2012), the Montevideo Meeting of Economics (Central Bank of Uruguay, December 21, 2012), Center for Global Development (March 2013), Aspen Network of Development Entrepreneurs Metrics Conference (June 2013) and seminars at James Madison University, Cornell University, Kurukshetra University and the Bill and Melinda Gates Foundation for helpful comments. Financial support from the U.S. Department of State (S-ECAAS-04-GR216 (MA)) and GWU's Institute for International Economic Policy is gratefully acknowledged. The standard disclaimers apply.
} 


\section{Introduction}

The goals and designs of poverty programs are increasingly framed by a multidimensional conception of poverty. A multidimensional poverty analysis is called for when individuals or families face multiple deprivations simultaneously, while individuals are understood to be poorer as the number of deprivations increases. This paper introduces the systematic analysis of multidimensional targeting and evaluation of poverty and other social programs. We contribute to the analysis of targeting mechanisms and evaluation frameworks for programs intended to reduce poverty in which deprivation is multidimensional, and multiple program activities and outcome objectives may all be relevant. Analogous principles apply for other social programs in which deprivations of concern can be enumerated.

The analysis provides a way to address two fundamental but generally overlooked questions: What roles do choices in numbers and types of screens play in determining the characteristics of individuals or households selected to participate in a program, and in the subsequent distributions of (summary measurement of) program outcomes across participants? How can sets of changes in program-related outcome variables or initial screening variables be summarized systematically (and with clearly-understood properties)?

We first demonstrate how poverty program impact can be accounted as changes in an appropriate multidimensional poverty measure; our approach parallels the multidimensional measurement technology of Alkire and Foster (2011). We compare changes in individual and multidimensional outcome measures for a treatment group that results from particular screening (inclusion) criteria, with the corresponding changes of a corresponding, matched control group.

As impact variables, we use sets of indicators that correspond to explicit programmatic goals. As a supplemental approach, we also examine changes in the set of characteristics that are used as initial screens.

We examine how initial characteristics and program outcomes would vary as the program eligibility screens are altered, an approach we call 'counterfactual targeting design.' Our ap- 
proach also offers an alternative framework to account for heterogeneity of program impacts across poverty levels.

We proceed to apply these methods to assess BRAC's Targeting the Ultra-poor Program, which formally required at least 3 of 5 screening criteria to be present for eligibility. BRAC is an indigenous NGO that is generally acknowledged as having a deep understanding of the nature of poverty in the region we study (Smillie 2009).

We compare characteristics of BRAC participants as we vary counterfactual participation targeting criteria, that is, as fewer or greater of BRAC's poverty indicators are required for inclusion. Then, we calculate impacts as corresponding changes in the screening variables, and as outcomes related to the program activities (we provide impact estimates both for multidimensional measures, as well as for individual indicators). We find impact heterogeneity in that the BRAC TUP program has significantly larger effects on health outcomes and reduction in child labor for the less multidimensionally (or extremely) poor among its selected participants. A central aspect of the TUP program is the transfer of assets. We find that the factor most driving poverty reduction is accumulation of assets - above and beyond any assets transferred by the program. Thus, the program may help establish participants on a path of asset accumulation.

In addition to BRAC, there is a more general tradition of other NGOs using key indicators of poverty for program participation. For example, CARE uses a menu of targeting indicators in its food security programs, such as height-for-age (CARE (accessed 2/23/2012)). Notice that our framework for the analysis of targeting differs fundamentally from proxy means approaches, in that we are not seeking to proxy for income (or of any other single indicator such as consumption or wealth). Instead, we utilize separate indicators for deprivations of more than one distinct type, as in BRAC programs. Thus the motivation for this approach is also above and beyond the concern that, in developing countries, income as well as consumption measurement is notoriously imprecise. In contrast, we are addressing cases in which programs and policies proceed from a multidimensional conception of poverty for which income 
is not a sufficient statistic - which is increasingly becoming a standard approach to measuring poverty and to conceptualizing the aims of poverty programs.

\section{Theory and Framework}

Poverty is increasingly understood as inherently multidimensional. Correspondingly, many programs simultaneously tackle multiple problems of poverty. Impact evaluations often present a long list of outcome variables, treating each one separately without a unified framework for treating the impact on poverty. In this section, we show how recent advances in multidimensional measurement technology can be extended to develop a new framework for multidimensional evaluation. At the same time, many social and poverty programs utilize several screening criteria in determining participant eligibility; we also introduce corresponding innovations in multidimensional targeting

In general, we will identify individuals as poor if they are deprived in a designated number $k>0$ dimensions, and identify them as ultra-poor if deprived in a sufficiently larger number $k+j$ dimensions. Related to the work of Atkinson (2003) we vary the poverty threshold $k$ to consider a recipient as fulfilling the criteria to be identified as poor from the case $k=D$ where the recipient is deprived in all dimensions, to the case $k=1$ where it suffices to be deprived in any one of the designated dimensions to be identified as poor, or otherwise eligible for participation in a program. An analogous structure applies to identification of the ultra-poor. We thus introduce a "counterfactual targeting" approach, in which characteristics of the target group are compared as the numbers (and potentially depths) of deprivations used as program screens are varied.

Moreover, we connect multidimensional targeting screens to evaluation criteria. We demonstrate how "counterfactual program evaluation" can be performed at different hypothetical poverty (eligibility) thresholds with appropriately constructed control groups.

We show how multidimensional impact assessment can be grounded in the multidimensional poverty measurement technology developed by Alkire and Foster (2011). This approach facilitates and clarifies analysis of program impact assessment with multiple relevant 
outcome indicators, as well as heterogeneity in the program effects. For a given extent of deprivations, the program outcomes may be assessed as successful or unsuccessful depending on the number of significant impacts and the size of those impacts. In one application, the program is deemed successful to the extent that the measure of participants' multidimensional poverty fell relative to that of the relevant control group. We calculate the difference in difference of the Alkire-Foster adjusted headcount ratio $M^{0}$ across participant and control groups. $M^{0}$ is equivalent to the product of the fraction of the sample in poverty, multiplied by the average fraction of deprivations among those in poverty. Among other properties, $M^{0}$ satisfies a dimensional monotonicity measurement principle, as described below.

\subsection{Multidimensional Targeting}

Targeting of the poor is carried out in a sequential process:

(i) Consider a selected set of $\mathrm{D}$ deprivation indicators $(\mathrm{d}=1, \ldots, \mathrm{D})$. This set may have been selected by government, a local community, or researchers, and is supposed to correspond to the contextually relevant concept of deprivation or poverty. At this stage, we take this set as given (chosen by a program designer, for example). For each set of targeting criteria, for each dimension, a dimension-specific threshold or poverty line (l) must be specified. If the individual is lacking in one of these indicators (or in a continuous case falls below a given threshold level), then she is identified as deprived in that dimension. Clearly, the number of eligible citizens will in general decline with the number of deprivations $k$ required for participation. Now individuals are classified in two subgroups, comprising those receiving the program treatment $(\mathrm{T})$, and the control group $(\mathrm{C})$. The program will designate the number of deprivations an individual must have to qualify for program participation (treatment) ${ }_{1}^{1}$. For evaluation purposes, we should have data for at least two periods; assume we have household data for two periods: baseline $(t=0)$ and follow-up $(t=1)$. In the second period, the

\footnotetext{
${ }^{1}$ Regardless of the other deprivation indicators, in practice a program may also choose to exclude individuals who have other characteristics that make it clear they are ineligible; but such "exclusion criteria" are outside the focus of this analysis.
} 
number of deprivation indicators may change (a decrease in $k$ for the treatment group may or may not be attributed to the treatment). Thus, there are four subsamples: $N_{i t}:\left\{N_{T 0} ; N_{C 0} ; N_{T 1} ; N_{C 1}\right\}$.

(ii) In each of these subsamples and for each period, the deprivation data generates a deprivation matrix $g=\left[g_{i j}\right]$ of dimensions $\left(N_{i t} \times D\right)$ where if the individual is deprived in one dimension, then she is assigned a value of one; if the individual is not deprived, she is assigned a value of zero. For identification (in the spirit of Sen), a threshold number of deprivations (zero-valued indicators) must be present. Formally, the identification of individual as deprived is a function $\rho(\cdot)$ of the individual deprivation vector and the cutoff vector: $\rho\left(d_{i} ; z\right)=1$ if a person is deprived in dimension $d_{i}$ and zero if not. Let the vector $c_{i t}$ of dimensions $\left(N_{i t} \times 1\right)$, such that $c_{i t}=\sum_{d=0}^{d=D} c_{i t d}$ be the total number of deprivations that each individual presents at each period. If it is the case that the deprivation indicators are ordinal or continuous, a deprivation-gap is also computed.

(iii) Then, if the individual is deprived in the designated number $k$ (or more) dimensions $\left(c_{i t}>k\right)$ then she is deemed multidimensionally poor (and if deprived in $k+j$ dimensions then "ultra-poor"). The poverty line here would be given by the cutoff $k+j$ number of dimensions to be considered ultra-poor. Thus, identification of the multidimensionally poor individuals is given by the function $\rho_{k}=(z, w, k)$. (We work with the benchmark case of equal weights, such that their sum equals the number of dimensions considered). If the person is identified as multidimensionally poor, the identification function takes a value of one; otherwise, it takes a value of zero. By multiplying each row of matrix $g$ by the identification function $\rho_{k}$, a censored-deprivation matrix $\left(g^{0}(k)=\left[g_{i j}^{0}\right]\right)$ can be generated, where now, if the person is not identified as multidimensionally poor, she is assigned a value of zero, even if in the previous matrix $g$ had a positive value in one specific dimension. Thus, the matrix $g^{0}(k)$ only displays information for the multidimensionally poor -completing the poverty identification phase. 
For the aggregation step, we construct multidimensional indicators of program impact, using the $M^{0}$ adjusted headcount ratio at each level of $k$.

Assume for the moment that $k$ is fixed at $1<k<D$. In this paper, in which our indicators are dichotomous, we calculate the headcount ratio $(\mathrm{H})$ and the adjusted headcount ratio $\left(M^{0}\right)$ poverty indicators. The headcount ratio is the mean of the (censored) deprivation matrix $g$; it indicates the proportion of the population who are poor. However, this measure is limited in that it does not conform to dimensional monotonicity in that the measure does not change if an already identified poor person becomes deprived in additional dimension(s).

In contrast, the adjusted headcount ratio combines two measures: the headcount ratio $\mathrm{H}$, and the average fraction of deprivations A (the number of deprivations that each poor household has divided by the total number of deprivations considered). The resulting adjusted headcount ratio measure also can be written as $H \times A$ (the product of the headcount ratio and the average intensity of poverty). In contrast to the simple multidimensional headcount $\mathrm{H}$, the adjusted headcount ratio satisfies dimensional monotonicity (if the average fraction of deprivations increases, so does $M^{0}$ ). The measure is both easy to compute and to interpret.

Note that in poverty program impact evaluation, at baseline the Headcount Ratio is equal to 1 at each poverty cutoff $k$, because only those who would be eligible for the program are included in the sample for analysis.

\subsection{Multidimensional Evaluation}

We estimate the program impact with the difference-in-difference (DID) estimator of either the eligibility indicators, or alternative sets of basic needs indicators. We examine how the program impact varies with eligibility thresholds, as the poverty cutoff ranges from fewest to most initial deprivations ${ }^{2}$

In some cases, the set of variables used for targeting will differ from the set of variables used for measurement of differences in changes in poverty. This could follow for various reasons; for example, the targeting variables might be more easily observable in the field for

\footnotetext{
${ }^{2}$ In this paper, we offer a descriptive analysis of counterfactual program impact; we do not claim that the estimated counterfactual impacts identify causality.
} 
initial classification of potential participants, or evaluators might prioritize different impacts than those doing the targeting. Thus, we also introduce an "integrated approach," by utilizing BRAC's five inclusion criteria for the multidimensional targeting, but then analyzing changes in the four basic needs indicators for the measurement of multidimensional impact. Otherwise, the approach is a straightforward combination of the methods outlined in sections 2.1 and 2.2 above.

\section{An empirical application:}

\section{Multidimensional Analysis of BRAC's Targeting the Ultra-poor Program, Phase I}

BRAC's Targeting the Ultra-poor Program (TUP) is an ideal setting for an empirical application of the preceding framework, because the relevance of each component of our approach is readily apparent, and specific choices for the evaluation metrics are also fairly transparent. In particular, the TUP program provides a context in which the underlying problems of poverty are explicitly understood in a multidimensional manner; in which multidimensional criteria are used to distinguish those living in the most extreme (ultra-)poverty from those whose poverty may also be deep but is above this level and in which program activities designed to respond to these programs are multidimensional by design. Thus it would follow quite naturally that multidimensional evaluation would be called for.

In this section, we apply our method to the BRAC Targeting the Ultra-poor program, and interpret the results in a multidimensional context. The results also illustrate how counterfactual targeting can reveal how single and multidimensional indicators of impact differ depending upon the screens used for program participants.

\subsection{Background on BRAC and the Ultra-poor Program}

By several measures BRAC 3 is one of the largest NGOs in the world. BRAC has extensive experience designing and implementing programs to alleviate the deprivations of the poorest

\footnotetext{
${ }^{3}$ The BRAC acronym currently stands for Building Resources Across Communities, and formerly stood for its better-known name, the Bangladesh Rural Advancement Committee.
} 
households. It has provided microfinance since 1974. After concluding that their standard microcredit programs did not engage most of the poorest, BRAC pioneered transitional programs to improve the readiness of the ultra-poor to participate in microfinance programs, or to otherwise graduate people out of ultra-poverty. In Bangladesh two types of programs were historically designed to alleviate poverty, structural and transitory (Matin 2004). In situations of structural poverty, with households permanently living below the poverty line, an anti-poverty program would provide them with enough income to escape from poverty. When households faced a negative transitory income shock, the proposed solution was to help them with one-time grants in order to return households above the poverty line (Matin 2004b, page 7). However, after the programs ended, households tended to return to their former poverty situation (BRAC 2002). In response, BRAC designed the CFPR/TUP program to take a comprehensive approach, providing households with an asset transfer, nutrition and other basic education, enterprise development training, social development, and health care, to put them in a position to withstand future adverse shocks and to gain the capability to benefit from BRAC's village organization (VO).

TUP (phase I) was launched in 2002 in three of the poorest districts in Northwest Bangladesh (Rangpur, Kurigram, and Nilphamari) selected on the basis of poverty mapping. The TUP program aims to improve the physical, human, and social capital of the poorest of the poor. A core activity of the program is to provide participants with a grant of specific physical assets. The TUP program then provides assistance and training for using the transferred assets effectively as a microenterprise. In particular, BRAC staff members offer ongoing training in specific enterprise activities notably livestock and poultry rearing, operation of tree nurseries, and village vending. Each training program is targeted to the specific asset transferred; periodic refresher training is offered. After enterprises are established, microfinance and related services are eventually provided through the equivalent of BRAC's primary Village Organizations. A goal of mainstreaming these clients into microfinance is to enable them to maintain and expand their businesses over time. The TUP program works to develop human capital through the microenterprise training, as well as 
general education including functional literacy, and improved health. BRAC staff including BRAC's village health volunteers known as Shastho Shebikas provide training, basic care, and referrals. Financial assistance for illness is also provided; and direct services include child health, immunization, diarrheal disease control, vitamin A supplements for children under 5 , TB control, family planning services and pregnancy care. Tube wells and sanitary latrines are installed, also for health benefits.

\subsection{Targeting in the BRAC Program}

We apply our methodology utilizing panel data from BRAC's Targeting the Ultra-poor (CFPR /TUP) program. First, we compare outcomes among those satisfying the current program threshold of poverty indicators ( $k+j=3$ in this program), with those of alternative poverty lines. We simulate different program eligibility thresholds by varying the numbers of deprivations defining the multidimensional poverty line. In each case, the treatment and control groups consist of those who would be eligible for participation for the given counterfactual criteria.

In the BRAC TUP program, to select participants, first, all members of treatment and comparison groups are nominated by villagers as among the poorest local families. Second, a subset is selected by BRAC according to multidimensional criteria of the general type described in the previous section. The exclusion criteria required that participating women must be capable of doing work outside the home; must not belong to another NGO program; and must not receive a food benefits card. 4

\footnotetext{
${ }^{4}$ In addition, there were three conditions, if any of which were met, would automatically exclude the household from consideration (irrespective of the levels of any deprivation indicators). These "exclusion criteria" were: (EC1) participating in another NGO; (EC2) receiving a VGD (Vulnerable Group Development) food card; (EC3) lacking any woman able to work in the household. Of the 5067 households in the 2002 dataset, 444 were participating in another NGO; 127 were recipients of the VGD card, and 48 had no women able to exert labor. Table A.3.a) shows the incidence of each criterion in the full sample, respectively $9 \%, 3 \%$, and $1 \%$. The first two criteria aim at excluding women because they have access to other programs. The rationale was to focus on women who were too poor to have sufficient social or political influence to receive the ration cards, or too marginalized for (other) NGOs to find or work with them. The third exclusion criterion aims at excluding women who were disabled, or who for some reason could not use an asset productively. The notion is that these women might benefit from a different program, such as direct relief or a longer-term development program. These women may or may not be ultra-poor; but as they are automatically excluded from participation in the program, it is not meaningful to include them in the analysis. Overall, $12 \%$ of the participants met at least one of the conditions for exclusion from the program.
} 
In the inclusion criteria, participating women have to meet three of the following: child labor is present; ownership of less than 10 decimals of land (a tenth of an acre); lack of a male earner at home; adult women selling labor outside of the household; and lack of any productive assets (Noor et al. 2004, p. ix, BRAC Annual Report 2007, p. 24). 5 Thus, in the framework of this paper, $k=3$; so if this were executed perfectly we would be limited to examining cases of $k=\{3,4,5\}$. However, in practice there was a sufficient incidence of mistargeting such that we are also able to examine cases of $k=\{0,1,2\}$.

To find such ultra-poor women, several strategies were used. One is "Participatory Wealth Ranking" that utilizes local information available to the villagers. A meeting is held in which villagers agree on a wealth ranking among the households. For example, those who can afford tin plate walls or roofs were viewed less poor than those with straw walls or thatched roofs. To keep the process manageable, only about 150 households were included in each wealth ranking exercise. To identify the poorest households four steps were followed: (i) rapport building; (ii) participatory rapid appraisal meetings; (iii) survey and preliminary selection; and (iv) final selection (Matin 2004). Our panel data set is comprised of women nominated by villages through this process - some of whom were ultimately selected by BRAC to participate in the program and others not.

\subsection{The Data and Variables Description}

The BRAC TUP Phase I data set is a two-year panel of about 5000 households. The baseline survey of 5626 households was collected in 2002. In 2005, 5288 households were resurveyed, along with 278 newly formed households that had split from the initial set of households. Attrition was moderate and was due to migration, death, and marriage; the matched panel

\footnotetext{
${ }^{5}$ In practice, some of these criteria did relatively little to distinguish the selected ultra-poor households from the other candidate poor households (NSUP), conditional on poverty status of other variables. Comparisons are made only among those nominated by villagers as likely to be among the poorest. While lack of homestead land is an indicator of lack of minimal security, it selected more than $90 \%$ of the 5067 households in the dataset. In practice, there is a relatively high correlation (0.89) between criteria IC2 and IC4, as both indicate that the candidate participant is likely to be the household head, and she might need to work outside home particularly in domestic work to sustain her family. The criterion aiming to identify households where there is child labor selects about 15\% of the households present in the 2002 dataset. (The working daughters and sons of many participants are older than the cutoff age for child labor). IC5 is more effectual for the purpose of sample separation as it has an intermediate incidence; it selects about half of the full sample as extremely poor.
} 
contained 5067 households. The dataset includes measures of household physical capital (land, rickshaw vans, fishing nets), human capital (schooling, child labor, health), and financial capital (cash savings). Data also measure basic needs (food security, clothing, and shoes/sandals), stocks of household durables, income, and potential indicators of women's empowerment. Cash savings is a binary variable that takes on the value of 1 if a household has cash savings in a given year. Food security is measured by two indicators. The first ranks 'food availability' in a household among four possible states: 'always deficit' [1], 'deficit sometimes' [2], 'neither deficit nor surplus' [3], or 'food surplus' [4]. The second indicator is a binary measure called 'two meals a day' that takes on the value of one when the household members can have at least two meals a day, and zero otherwise. The clothing variable refers to the main type of female clothing in Bangladesh: saris. 'Shoe/sandal' is a binary variable with a value of one when all the household members own shoes or sandals and zero otherwise. Physical assets include livestock (cows/bulls, ducks, hens, etc.) and other productive assets (such as a fishing nets, rickshaw vans, and "big trees"). The asset measures do not include any assets transferred from the TUP program. Household durable goods include tube wells as well as chairs, beds, radios, TVs and quilts ${ }^{6}$ There are two indicators on subjective health conditions reported by the respondents. The 'health status' variable asks the respondent to rank his/her perceived current health status given five options: Excellent [5], Very good [4], Good [3], Fair [2], Poor/Bad [1]. The second health indicator is 'health improvement' that ranks one's health compared to last year among five possible cases: Much better than one year ago [5]; somewhat better now [4]; about the same [3], somewhat worse [2]; much worse $]^{7}$ As indicators of women's welfare and empowerment we use the proportion of child labor among girls, and schooling of girls. ${ }^{8}$ (Tables A.1 and A.2 presents the summary statistics of the relevant outcome variables used in this paper.)

\footnotetext{
${ }^{6}$ Our analysis covers both flow and stock variables; an observation after three years may underestimate the long term effects of the program.

${ }^{7}$ We note that the subjective health indicators may be measured with error in the sense that the TUP program raises health awareness of the participants; and thus a negative response might reflect that an individual is better aware of the preexisting conditions, rather than an actually worsening health status.

${ }^{8}$ We note that these indicators of women's welfare and empowerment are the best available in this dataset, but are inherently limited.
} 


\subsection{Multidimensional Targeting}

\subsubsection{Identification of Poor Households According to the Type and Number of Screens Used}

As mentioned, after the household survey was conducted, five criteria for program participation were utilized, of which a sufficient number (3) had to be met to classify the household as ultra-poor.

\subsubsection{Eligibility criteria}

There was a set of five criteria of inclusion into the program. These were: (IC1) ownership of less than 10 decimals of land, (IC2) no male income earner at home, (IC3) children of school age having to work, (IC4) household dependent upon female domestic work outside the household, and (IC5) households having no productive assets. Table A.3.b) presents the number of households selected in 2002 by each poverty indicator. All households in the sample, both participants and nonparticipants, should exhibit at least one of these five deprivation criteria. In addition, some households who did not exhibit any eligibility criteria were nevertheless present in the sample (most of them as part of the control group) ${ }^{9}$

\subsubsection{Ultra-poor status}

The final layer for identification of ultra-poor households follows from the number of criteria $k$ established for the multidimensional poverty line. The program set the poverty line at $k$ $=3$, that is, to be chosen, households had to eligible by meeting at least three of the five inclusion criteria, while at the same time not being disqualified by any of the three exclusion criteria 10 . We emphasize that our analysis is not intended to question BRAC's design of the program in designating three (or more) out of five indicators as its formal poverty threshold for participation. Instead, our approach is motivated by five general observations. First,

\footnotetext{
${ }^{9}$ There were 202 households in the sample who presented no eligibility criterion; and among them, 48 presented at least one criterion for exclusion.

${ }^{10}$ Complete sets of additional background descriptive statistics, such as the numbers included for each criteria, are available from the authors.
} 
across programs and in different settings, $k=3$ is an arbitrary cutoff value ${ }^{11}$ Second, after collection and analysis of baseline data, additional information is available to reconsider targeting design. Third, if a program budget constraint becomes relaxed, the targeting of additional resources may depend on characteristics of those potentially eligible. Fourth, our approach allows for targeting design provided that information can be used for baseline information; this can include household surveys or poverty mapping approaches. Fifth, it allows for a new form of sensitivity analysis to introduce along with multidimensional evaluation.

\subsection{Aggregation of the poor: calculation of $M^{0}$ Indicator}

For the derivation and analysis of the $M^{0}$ indicator, we restrict the sample to the 4316 households that in 2002 presented at least one deprivation, and analyze the change in their poverty indicator in the 2005 follow-ur ${ }^{12}$

Table 1 is presented in two horizontal panels, the first one is for the baseline period and the second for the follow-up. They are interrelated because the Headcount Ratio in the follow-up period is normalized with respect to the baseline number of households in each subgroup (treatment and control) at each poverty threshold. The first horizontal block of Table 1 presents the number of households selected at each poverty threshold in 2002 . Then, looking at the table by columns, column (a) indicates the number of deprivations considered as poverty threshold for each line. Column block (b) indicates the total number of households selected by $k$, and how many of these household belonged to the initial treatment/control group. The initial classification between treatment and control remains unchanged for the whole period; what does change is the sub-classification of households according to how many deprivations they present in each period. In column block (c), $\mathrm{H}$ is the fraction of the relevant sample living in (multidimensional) poverty at the corresponding initial cutoff of required numbers of deprivations. In the initial period, all of the resulting individuals with numbers

\footnotetext{
${ }^{11}$ Indeed, as examined below, within this program this single cutoff was not rigorously adhered to in practice; some participants were included despite having fewer inclusion criteria, and some were excluded despite having more.

${ }^{12}$ We present the analysis for the whole sample in Table A.5 and to some extra sub-partitions: those excluded and those who did not present any deprivation criteria at baseline. Among those 5067, 202 households presented no deprivations at all $k \equiv 0$, distributed as 26 in the treatment group and 176 in the control group.
} 
of deprivations at or above the selected cutoff are by definition poor, thus $\mathrm{H}$ is equal to one, by construction. In each case, corresponding values are calculated for the fraction of indicators for which households identified as poor are deprived on average (A). For each cutoff $k$, the corresponding values for A are reported in column block (d). Note that with a $k$ cutoff of 5 , all such individuals are deprived in all 5 indicators, and thus their value for A is 1 by construction. For each lower poverty cutoff, the value for A successively falls, because it averages in corresponding individuals whose deprivations are progressively fewer than 5 . A simple expression for the adjusted headcount ratio, $M^{0}$ is the product, $H \times A$. The calculated values for $M^{0}$ are presented in the column block (e), which are identical to $A$ in the baseline, as $\mathrm{H}$ is normalized to one.

In 2002, the treatment group presents a significantly larger number of deprivations than the control group, for $k=1$ to $k=3$. The $M^{0}$ indicator, depicted in the last columns of Table 1 shows that, as expected, with increasing number of deprivations considered in the poverty threshold, the breadth of poverty increases. At $k=3$, which is the official poverty threshold stated by BRAC, the treatment group is 27 percent multidimensionally poorer than the control group, as measured by $M^{0}$. Stated in this raw, unadjusted way, there appears to have been "negative selection" into the program.

The second horizontal block in Table 1 shows the calculation of the $M^{0}$ indicator for 2005 . Now the poverty threshold starts at $k=0$ because there are 124 households of the initial 4316 who present zero deprivations. Note however, that 17 percent of them belong to the control group and 11 percent to the treatment group. Because they have zero deprivations, the $M^{0}$ indicator is equal to zero by construction. Note again that in 2005 the classification of households between treatment and control groups is a definition and does not change in the analysis; however, the number of deprivations that households present does vary with respect to 2002. For example, it might be the case that all the 129 households that had all five deprivations in 2002 now in 2005 have no deprivations at all, and that some households that had initially strictly less than 5 deprivations in 2002 present in 2005 all 5 deprivations. 
We further note that by 2005 , in most cases, the average share of deprivations for the treatment group became smaller than for the control group (although not monotonically). Moreover, for the poverty thresholds $k=2$ to $k=5$, the headcount ratio is smaller for the treatment group than for the control group. These indicators are consistent with program success.

\section{Multidimensional Targeting: Alternative Measures}

\subsection{Changes in Multidimensional Basic Needs Measures: Analysis of Sets of Program Outcome Variables}

Thus far, our measure of multidimensional poverty has been based upon what may be understood as an implicit definition used by BRAC in determining whether an individual is deprived enough to qualify for participation in its ultra-poverty program, namely the number of screening indicators present. An analogous exercise can be done with the use of other deprivation criteria, whether established by researchers, or by other programs to correspond to their own local context.

In general, screening indicators are not necessarily the most appropriate components for multidimensional poverty measurement and program evaluation. This is because although screens may provide ready proxies for identifying the poor, they may not encompass the underlying concept of poverty, or the actual activities addressing deprivations that are at the focus of the program. Additional criteria for dimensions to include may be considered, such as basic capabilities and assets that might be directly or indirectly impacted by the program. So, a major alternative that we explore in this section is to build the poverty measure with a set of key variables that correspond to program objectives (perhaps better capturing the concept of ultra-poverty than can the screens for participation eligibility), or other established features of poverty. This also allows for a more complete separation of poverty identification and poverty measurement. 


\subsubsection{Selection of Deprivations for the Alternative Multidimensional Poverty Mea- sure}

The TUP program was intended to address the range of basic needs of the poorest of the poor; so in this case indicators of program activities and the incidence of major deprivations are closely related. Accordingly, we selected four fundamental deprivation indicators: food security, health status, housing quality, and clothing - each of these represent basic needs ${ }^{13}$ For food security, we use the variable 'inability to eat meals twice a day.' For health, we use the lowest two answers on subjective health status (fair and bad) from a five-point scale. For housing quality, we use 'low-quality roof.' Finally, for clothing and shoes, the deprivation indicator equals one if the individual owns no shoes, and/or owns only one saree; and equals zero if she owns shoes and more than one saree. ${ }^{14}$ We index the new outcome-deprivations with the letter $j$ to clarify exposition. We use these four dichotomous variables to construct a corresponding aggregate measure of poverty $M^{0}$, varying the number of these deprivations $j=(1,2,3,4)$. For additional perspective, we also consider the number of deprivations as alternative inclusion criteria for program participation.

We present the construction of the basic needs multidimensional deprivation indicators in Table 2, calculated from the 4316 households from the full sample that had at least one BRAC targeting criteria present. This alternative indicator shows that about ten percent of the households at the start of the program do not have any of the four deprivations selected for the new measure (185 of them in the control group and 293 in the treatment).

From $j=1$ to $j=4$, the number of households in the treated group is substantially larger than that of the control group, as are the average share of deprivations. Moreover, blocks (c) and (d) indicate that the treatment group was somewhat poorer in the baseline year 2002, in the sense that those identified as poor have a larger number of deprivations on average. The

\footnotetext{
${ }^{13}$ Clearly, greater or fewer deprivations can be included in the measure, as concerns broaden or narrow. For program evaluation, we can give this choice more structure by having the impact measures relate to program features. The point is that this method is broad and can be applied with different perspectives on a program, or as sensitivity checks on measuring its impact.

${ }^{14}$ We note that in the current example changes would represent an indirect program impact, as there was no explicit program component to address clothing deficits.
} 
$M^{0}$ indicator for 2002 suggests that the treatment group is significantly more deprived than the control group, at $j=1$ and $j=2$ thresholds.

The point is that this method is broad and can be applied with different perspectives on a program, or as sensitivity checks on measuring its impact. We note that in the current example changes would represent an indirect program impact, as there was no explicit program component to address clothing deficits. The calculation for the year 2005 shows that the treated households now have both a smaller headcount ratio and a smaller number of deprivations, both effects resulting in a lower value for $M^{0}$.

\subsection{An integrated approach}

In this section we introduce an integrated approach, combining counterfactual targeting (according to number of screens for participation) with multidimensional impact evaluation, and demonstrate its application. We use the initial five BRAC deprivation (inclusion) criteria to construct several corresponding values for the alternative $M^{0}$ indicator using the four basic needs outcome variables.

In Tables 3 and 4 , we present calculations of $M^{0}$ for 2002 and 2005 respectively, in which we define the targeted subgroups according to BRAC's targeting criteria, while using changes in the basic needs indicators for constructing corresponding values of $M^{0}$. This supplemental approach is followed for reasons outlined in Section 2.3; the calculations and interpretations are otherwise analogous to those of Tables 1 and 2.

Table 3 presents the change in the multidimensional outcomes indicator for those households that initially had at least one of the five deprivation (inclusion) criteria. The analysis considers the subgroup of 4316 households that in 2002 presented at least one deprivation. In addition, separated by a dashed-line, we present the change in the multidimensional outcomes indicator, with poverty threshold $k=3$. We use the four dichotomous basic needs variables (inability to take meals twice a day, poor health status, low-quality housing and lack of shoes/sarees to construct the corresponding aggregate measure of poverty $M^{0}$, varying the number of these deprivations $j=(0,1,2,3,4)$ to represent different cutoff degrees of 
poverty. The first horizontal block comprises the sample of individuals selected in 2002 by the alternative criteria. The second block shows the final year 2005. In column $1, j$ indicates the minimum number of deprivations criteria that the household presents; $\mathrm{N}$ counts the number of households selected by $j ; \mathrm{H}$ is the headcount ratio; $\mathrm{A}$ is the average fraction of deprivations (the number of deprivations that each households has divided by the total number of deprivations considered); $M^{0}$ is the Adjusted Headcount Ratio (the product of $\mathrm{H}$ and A). Accordingly, we can show how a multidimensional deprivation indicator varies with number of screening variables - making a clear separation between the two concepts.

These results suggest that there was heterogeneity in starting multidimensional poverty; and, by these measures, negative selection into the program. They also reveal that these gaps shrunk by 2005, as program participants experienced more rapid reduction in multidimensional poverty than did nonparticipants.

\subsection{Multidimensional Evaluation}

\subsubsection{Using the Set of Screening Criteria for Multidimensional Poverty Impact}

Our principal multidimensional poverty impact indicator is the difference in the difference in the resulting poverty level $M^{0}$, for each cutoff value $k$. Results are reported in Table 5 . We augmented the DID estimation by including a set of controls at baseline: household size, amount of land owned, whether the female was working as a day-laborer and whether the household head was a female. Quantitatively, all columns show that the measured impact (DID) of the program on poverty was quite substantial. The impacts were larger, the poorer the sample (as measured by the number of initial deprivations). The reduction in poverty at $k=1$ was 9 percent, at $k=2$ was 20 percent, at $k=3$ was 26 percent and at $k=4$ was 58 percent. Because we constructed the subgroups of varying $k$ as the joint change of $(i)$ number of households with $k$ deprivations and (ii) average share of deprivations, it turns out, for example, that all the households in the treatment group that had 5 deprivations in 2002, had strictly less than 5 deprivations in 2005. Thus, the DID presented in this table is not exactly the difference between the change in 2005 minus the change in 2002 from Table 1. 
One of the key properties of the $M^{0}$ indicator is its ability to summarize all deprivations in one single, readily interpretable number. Further, we can discover which deprivation reductions explain the overall poverty reduction. Thus, in Table 6, we decompose the changes in $M^{0}$ to examine the differences - and the difference-in-differences - for each component element. The results of this exercise reveal that the acquisition of assets is the largest factor explaining the decrease in the multidimensional poverty indicator. It should be noted that while the program itself transferred assets, these transfers are netted out - significant numbers of participants have acquired assets above and beyond those provided by the program.

The use of difference-in-difference is plausible: the treatment and control have corresponding numbers of actual deprivations in each case, so that those eligible for the program who did participate are compared with those who would be eligible, but who nonetheless did not participate.

However, this example already demonstrates the practicality of using our proposed method for multidimensional program targeting and evaluation, applied to deprivation criteria for poverty program participation. In each case, we calculate the change in the poverty rates before and after the program as we vary the poverty threshold $k>0$. Utilizing the multidimensional adjusted headcount measure $\left(M^{0}\right)$, we found that the variously defined treatment groups consistently exhibited greater poverty reduction than carefully matched control groups.

We now turn to the analysis of the difference-in-difference estimator using the basic needs indicators.

\subsubsection{Using the Set of Basic Needs Indicators for Multidimensional Poverty Im- pact}

In Table 7, we present the results of the DID estimation, which suggest substantial multidimensional impacts of the program for each cutoff $j$. Despite the 'negative selection' shown in the previous table -and despite the fact that, on average, multidimensional poverty fell for all subgroups of both treatment and control, the largest program impacts are found among the most deprived participants in relation to their corresponding control groups. For most of 
the subgroup impacts considered, a more exacting identification strategy would be needed to establish causality

The DID results indicate a large impact of the TUP program on poverty, significant at the $1 \%$ level for the subgroups with initially one, two, three or four deprivations (for $j=1,2,3,4$ ). For program participants, multidimensional poverty - as measured with the four basic needs indicators - decreased 18.5 percentage points more than the control group for the sample that included the less extremely poor, those who had one or more deprivations ( for $j=1,2,3,4$ ), and decreased by 35 percentage points more than the control group when considering all four deprivations.

Similar to the analysis done above for the $M^{0}$ indicator based on the TUP targeting criteria, in Table 8, we decompose the changes in $M^{0}$ to examine the differences - and the difference-in-differences - across key programmatic outcomes. In this case, the change in the outcome that is most responsible for the decrease in poverty is 'inability to take meals twice a day'.

In table 9, we present the DID coefficients corresponding to each of the five levels of screening $(k=1, \ldots, 5)$ and each of the four levels of deprivations $(j=1, \ldots, 4)$. The pattern of significance conforms to the other evidence that larger impacts are found among those who start with a greater extent of multidimensional poverty.

\section{Concluding Remarks}

This paper has assessed the design of targeting mechanisms in anti-poverty programs that are conceptualized as multidimensional, where many different deprivation dimensions are simultaneously addressed with the objective of pushing the households sustainably out of poverty. We propose a way of considering the type, number and specific sets of combinations to be satisfied. We connected the multidimensional methodology to the impact evaluation of programs. Using Alkire and Foster $(2007,2011)$ poverty measures H (Headcount Ratio) and $M^{0}$ (Adjusted Headcount Ratio) we showed how to evaluate the performance of an antipoverty program by calculating the change over time of the difference in difference of multi- 
dimensional poverty measures. In addition, the Alkire and Foster methodology $(2007,2011)$ allows us to decompose the poverty measure into its deprivation components to determine which one is responsible for the variation in poverty levels.

We provide a detailed application of our proposed approach with the analysis of the CFPR/TUP program using the Phase I panel dataset. According to the measure $M^{0}$ across initial number of deprivations, poverty decreased 26 percent at the nominal program cutoff of $k=3$. In several cases ( $k=1$ to $k=4)$ the DID of $M^{0}$ is substantial in magnitude and statistically significant. We also find a heterogeneous effect across households. Those with more deprivations experience a greater program impact on the probability of having cash savings, on the food security outcomes and on the probability of having shoes. Moreover, we constructed a multidimensional indicator of major deprivations directly or indirectly related to the program activities. Analysis revealed that the decrease in poverty varied - from 5.4 percent when poverty reduction was understood as a decrease in at least one (any) deprivation - to 42 percent when poverty reduction was considered as a decrease in at least four outcome-deprivation indicators.

Another general perspective emerging from the study is that the deprivation criteria used in targeting design should not be too highly correlated. The fraction deprived in each criteria and correlation of deprivations across households helps in deciding the relevancy of each indicator. For example, a criterion that selected as participants all households would not be suitable at identifying the poorest among them. A baseline survey of a sample of households should help to determine relevant indicators when introducing a program more broadly.

In conclusion, when poverty and other social programs have multiple goals and potentially important outcomes, a problem for assessment is posed when some indicators show notable improvements and others little or no change. We propose to assess such programs with multidimensional indicators, to complement the underlying or parallel individual outcome indicators. We showed that this could be done by connecting the multidimensional identification and measurement literature with the evaluation and targeting literature; and applied the approach to examine the impact of an innovative ultra-poverty program in Ban- 
gladesh. Moreover, we showed how the approach could be useful for counterfactual targeting assessing the characteristics of program recipients and measures of their program outcomes according to a varying number of dimensions of program screening indicators. We considered evaluation of individual impact indicators as the number of screens for participation varied. Finally, we introduced an approach to measuring program impact as the differencein-difference of multidimensional poverty measures between treatment and control groups.

\section{References}

Alkire, S., \& Foster, J. 2011a. Counting and Multidimensional Poverty Measurement. Journal of Public Economics, 95(7), 476-487.

Alkire, S., \& Foster, J. 2011b. Understandings and Misunderstandings of Multidimensional Poverty Measurement. Journal of Economic Inequality, 1-26.

Alkire, S., \& Santos, M.E. 2010. Acute Multidimensional Poverty: A New Index for Developing Countries,? Oxford Poverty and Human Development Initiative. Tech. rept. Working Paper 38, University of Oxford.

Alkire, S., Foster, J., \& Santos, M.E. 2011. Where did Identification Go? Journal of Economic Inequality, 1-5.

Atkinson, A.B. 2003. Multidimensional Deprivation: Contrasting Social Welfare and Counting Approaches. Journal of Economic Inequality, 1(1), 51-65.

Bennett, C.J., \& Mitra, S. 2011. Multidimensional Poverty: Measurement, Estimation, and Inference. OPHI Working Papers.

Besley, T., Kanbur, S.M.R., \& of the Vice President, World Bank. Office. 1990. The Principles of Targeting. Vol. 385. Office of the Vice President, Development Economics, World Bank.

CARE. accessed 2/23/2012. Proposed new Menu of Impact Indicators.

Catholic Relief Services. 2012. Microfinance.

Duclos, J.Y., Sahn, D.E., \& Younger, S.D. 2006. Robust Multidimensional Poverty Comparisons. The Economic Journal, 116(514), 943-968.

Emran, M.S., Robano, V., \& Smith, S. 2009. Assessing the Frontiers of Ultra-Poverty Reduction: Evidence from CFPR/TUP, an Innovative program in Bangladesh.

Foster, J., Greer, J., \& Thorbecke, E. 1984. A Class of Decomposable Poverty Measures. Econometrica: Journal of the Econometric Society, 52, 761-766.

Matin, I., \& Halder, S.R. 2007. Combining Methodologies for Better Targeting of the Extreme Poor: Lessons from BRAC's CFPR / TUP Programme. Tech. rept. eSocialSciences. 
Noor, M., Shihab, A.M., Parveen, R., Rahman, H., Ali, T., Zaman, S., \& Matin, I. 2004. Stories of Targeting. BRAC CFPR / TUP Working Paper Series.

Oxfam. 2012. Poverty scorecards - a cheap way to identify who's poor?

Ravallion, M. 2011. On Multidimensional Indices of Poverty. Journal of Economic Inequality.

Ravallion, M., \& Bank, World. 2007. How relevant is targeting to the success of an antiPoverty program? The World Bank.

Sen, A. 1976. Poverty: an Ordinal Approach to Measurement. Econometrica: Journal of the Econometric Society, 219-231.

Sen, A. 1980. Equality of what? The Tanner lectures on human values, 1, 353-369.

Sen, A.K. 1999. Development as Freedom. Oxford University Press.

Smillie, I. 2009. Freedom from Want: The remarkable success story of BRAC, the global grassroots organization that's winning the fight against Poverty. Kumarian Pr.

Smith, S.C. 2005. Ending Global Poverty: A Guide to What Works. Palgrave Macmillan New York.

Van de Walle, D. 1998. Targeting Revisited. The World Bank Research Observer, 13(2), 231248. 
Table 1: Calculation of $M^{0}$ Using BRAC Targeting Criteria as Implicit Poverty Indicators

\begin{tabular}{|c|c|c|c|c|c|c|c|c|c|c|c|}
\hline \multirow{2}{*}{$\begin{array}{c}\text { Year } \\
\text { (a) } \\
2002\end{array}$} & \multicolumn{3}{|c|}{ Number of obs } & \multicolumn{2}{|c|}{$\begin{array}{l}\text { Headcount } \\
\text { Ratio } \\
\text { (c) }\end{array}$} & \multicolumn{3}{|c|}{$\begin{array}{c}\text { Average share } \\
\text { of Deprivations } \\
\text { (d) }\end{array}$} & \multicolumn{3}{|c|}{$\begin{array}{c}M^{0} \text { Indicator } \\
=H \times A \\
(\mathrm{e})\end{array}$} \\
\hline & $\mathrm{N}$ & Control & Treated & Control & Treated & Control & Treated & Difference & Control & Treated & Difference \\
\hline $\mathrm{k}=1$ & 4316 & 2069 & 2247 & 1.000 & 1.000 & 0.435 & 0.530 & $\begin{array}{l}-0.095^{* * *} \\
(0.007)\end{array}$ & 0.435 & 0.530 & $\begin{array}{l}-0.095^{* * *} \\
(0.007)\end{array}$ \\
\hline $\mathrm{k}=2$ & 3262 & 1418 & 1844 & 1.000 & 1.000 & 0.543 & 0.602 & $\begin{array}{l}-0.059 * * * \\
(0.007)\end{array}$ & 0.543 & 0.602 & $\begin{array}{l}-0.059 * * * \\
(0.007)\end{array}$ \\
\hline $\mathrm{k}=3$ & 1727 & 641 & 1086 & 1.000 & 1.000 & 0.715 & 0.742 & $\begin{array}{l}-0.027 * * * \\
(0.006)\end{array}$ & 0.715 & 0.742 & $\begin{array}{l}-0.027 * * * \\
(0.006)\end{array}$ \\
\hline $\mathrm{k}=4$ & 1013 & 332 & 681 & 1.000 & 1.000 & 0.823 & 0.827 & $\begin{array}{l}-0.004 \\
(0.004)\end{array}$ & 0.823 & 0.827 & $\begin{array}{l}-0.004 \\
(0.004)\end{array}$ \\
\hline $\mathrm{k}=5$ & 129 & 38 & 91 & 1.000 & 1.000 & 1.000 & 1.000 & $\begin{array}{l}0.000 \\
(0.000)\end{array}$ & 1.000 & 1.000 & $\begin{array}{l}0.000 \\
(0.000)\end{array}$ \\
\hline 2005 & $\mathrm{~N}$ & Control & Treated & Control & Treated & Control & Treated & Difference & Control & Treated & Difference \\
\hline $\mathrm{k}=0$ new & 124 & 75 & 49 & 0.036 & 0.022 & 0.000 & 0.000 & $\mathrm{n} / \mathrm{a}$ & 0.000 & 0.000 & $\mathrm{n} / \mathrm{a}$ \\
\hline $\mathrm{k}=1$ & 4192 & 1994 & 2198 & 0.964 & 0.978 & 0.427 & 0.412 & $\begin{array}{l}0.015^{*} \\
(0.007)\end{array}$ & 0.412 & 0.403 & $\begin{array}{l}0.008 \\
(0.006)\end{array}$ \\
\hline $\mathrm{k}=2$ & 2553 & 1260 & 1293 & 0.889 & 0.701 & 0.559 & 0.560 & $\begin{array}{l}-0.001 \\
(0.006)\end{array}$ & 0.497 & 0.393 & $\begin{array}{l}0.104^{* * * *} \\
(0.005)\end{array}$ \\
\hline $\mathrm{k}=3$ & 1525 & 659 & 866 & 1.028 & 0.797 & 0.704 & 0.639 & $\begin{array}{l}0.065^{* * *} \\
(0.005)\end{array}$ & 0.724 & 0.510 & $\begin{array}{l}0.214^{* * *} \\
(0.005)\end{array}$ \\
\hline $\mathrm{k}=4$ & 470 & 305 & 165 & 0.919 & 0.242 & 0.826 & 0.807 & $\begin{array}{l}0.018^{* *} \\
(0.006)\end{array}$ & 0.758 & 0.196 & $\begin{array}{l}0.563^{* * *} \\
(0.005)\end{array}$ \\
\hline $\mathrm{k}=5$ & 45 & 39 & 6 & 1.026 & 0.066 & 1.000 & 1.000 & $\begin{array}{l}0.000 \\
(0.000)\end{array}$ & 1.026 & 0.066 & $\begin{array}{l}0.960 \\
(0.000)\end{array}$ \\
\hline
\end{tabular}

Notes: (1) The analysis considers the subgroup of $4316 \mathrm{HH}$ that in 2002 presented at least one deprivation. (2) Standard errors in parentheses. Significance levels are denoted as $* * * p<0.01 ; * * p<0.05 ; * p<0.1$. 
Table 2: Calculation of $M^{0}$ According to Basic Needs Indicator

\begin{tabular}{|c|c|c|c|c|c|c|c|c|c|c|c|}
\hline \multirow{2}{*}{$\begin{array}{l}\text { Year } \\
\text { (a) } \\
2002\end{array}$} & \multicolumn{3}{|c|}{ Number of obs } & \multicolumn{2}{|c|}{$\begin{array}{l}\text { Headcount } \\
\text { Ratio } \\
\text { (c) }\end{array}$} & \multicolumn{3}{|c|}{$\begin{array}{c}\text { Average share } \\
\text { of Deprivations } \\
\text { (d) }\end{array}$} & \multicolumn{3}{|c|}{$\begin{array}{c}M^{0} \text { Indicator } \\
=H \times A \\
(\mathrm{e})\end{array}$} \\
\hline & $\mathrm{N}$ & Control & Treated & Control & Treated & Control & Treated & Difference & Control & Treated & Difference \\
\hline $\mathrm{j}=0$ & 478 & 293 & 185 & 1.000 & 1.000 & 0.000 & 0.000 & $\mathrm{n} / \mathrm{a}$ & 0.000 & 0.000 & $\mathrm{n} / \mathrm{a}$ \\
\hline $\mathrm{j}=1$ & 3838 & 1776 & 2062 & 1.000 & 1.000 & 0.469 & 0.530 & $\begin{array}{l}-0.061^{* * *} \\
(0.007)\end{array}$ & 0.469 & 0.530 & $\begin{array}{l}-0.061^{* * *} \\
(0.007)\end{array}$ \\
\hline $\mathrm{j}=2$ & 2509 & 1061 & 1448 & 1.000 & 1.000 & 0.617 & 0.649 & $\begin{array}{l}-0.032 * * * \\
(0.007)\end{array}$ & 0.617 & 0.649 & $\begin{array}{l}-0.032 * * * \\
(0.007)\end{array}$ \\
\hline $\mathrm{j}=3$ & 1067 & 397 & 670 & 1.000 & 1.000 & 0.812 & 0.822 & $\begin{array}{l}-0.010 \\
(0.007)\end{array}$ & 0.812 & 0.822 & $\begin{array}{l}-0.010 \\
(0.007)\end{array}$ \\
\hline $\mathrm{j}=4$ & 290 & 98 & 192 & 1.000 & 1.000 & 1.000 & 1.000 & 0.000 & 1.000 & 1.000 & 0.000 \\
\hline 2005 & $\mathrm{~N}$ & Control & Treated & Control & Treated & Control & Treated & Difference & Control & Treated & Difference \\
\hline $\mathrm{j}=0$ & 886 & 318 & 568 & 1.085 & 3.070 & 0.000 & 0.000 & $\mathrm{n} / \mathrm{a}$ & 0.000 & 0.000 & $\mathrm{n} / \mathrm{a}$ \\
\hline $\mathrm{j}=1$ & 3430 & 1751 & 1679 & 0.986 & 0.814 & 0.451 & 0.408 & $\begin{array}{l}0.042^{* * * *} \\
(0.007)\end{array}$ & 0.444 & 0.332 & $\begin{array}{l}0.112 * * * \\
(0.006)\end{array}$ \\
\hline $\mathrm{j}=2$ & 1855 & 1026 & 829 & 0.967 & 0.573 & 0.593 & 0.571 & $\begin{array}{l}0.022^{* * * *} \\
(0.006)\end{array}$ & 0.573 & 0.327 & $\begin{array}{l}0.246^{* * *} \\
(0.005)\end{array}$ \\
\hline $\mathrm{j}=3$ & 540 & 332 & 208 & 0.836 & 0.310 & 0.786 & 0.781 & $\begin{array}{l}0.005 \\
(0.008)\end{array}$ & 0.657 & 0.243 & $\begin{array}{l}0.415^{* * * *} \\
(0.005)\end{array}$ \\
\hline $\mathrm{j}=4$ & 74 & 48 & 26 & 0.490 & 0.135 & 1.000 & 1.000 & $\begin{array}{l}0.000 \\
(0.000)\end{array}$ & 0.490 & 0.135 & $\begin{array}{l}0.354 \\
(0.000)\end{array}$ \\
\hline
\end{tabular}

Notes: (i) Selected program activities are: inability to take meals twice a day, bad health status, low-quality housing and combination of shoes and sarees. For food security, we selected the variable 'inability to eat meals twice a day.' For health, we selected the lowest two answers on subjective health status (fair and bad) from a five-point scale. For housing quality, we selected 'low-quality roof.' Finally, for clothing and shoes, the deprivation indicator equals one if the individual owns no shoes, and/or owns only one saree; and equals zero if she owns shoes and more than one saree. We use these four dichotomous variables to construct a corresponding aggregate measure of poverty $M^{0}$, varying the number of these deprivations $j=(0,1,2,3,4)$ to represent different cutoff degrees of poverty. (ii) The first horizontal block comprises the sample of individuals selected in 2002 by the alternative criteria that had at least one deprivation as measured by BRAC. Initial sample number is thus 4316 households. (iii) The second block shows the final year 2005. (iv) $j$ in column 1 indicates the minimum number of deprivations criteria that the household presents; $\mathrm{N}$ counts the number of households selected by $j ; \mathrm{H}$ is the headcount ratio; $\mathrm{A}$ is the average fraction of deprivations (the number of deprivations that each households has divided by the total number of deprivations considered); $M^{0}$ is the Adjusted Headcount Ratio (the product of $\mathrm{H}$ and A). (v) Standard errors in parentheses. Significance levels are denoted as $* * * p<0.01 ; * * p<0.05 ; * p<0.1$ 
Table 3: Calculation of $M^{0}$ Defining Subgroups According to BRAC targeting criteria and Basic Needs Indicators for Evaluation, 2002

\begin{tabular}{|c|c|c|c|c|c|c|c|c|c|c|c|}
\hline \multirow{2}{*}{$\begin{array}{c}\text { Year } \\
\text { (a) } \\
2002\end{array}$} & \multicolumn{3}{|c|}{ Number of obs } & \multicolumn{2}{|c|}{$\begin{array}{l}\text { Headcount } \\
\text { Ratio } \\
\text { (c) }\end{array}$} & \multicolumn{3}{|c|}{$\begin{array}{c}\text { Average share } \\
\text { of Deprivations } \\
\text { (d) }\end{array}$} & \multicolumn{3}{|c|}{$\begin{array}{c}M^{0} \text { Indicator } \\
=H \times A \\
(\mathrm{e})\end{array}$} \\
\hline & $\mathrm{N}$ & Control & Treated & Control & Treated & Control & Treated & Difference & Control & Treated & Difference \\
\hline \multicolumn{12}{|l|}{$\mathbf{k}=\mathbf{1}$} \\
\hline $\mathrm{j}=0$ & 478 & 293 & 185 & 1.000 & 1.000 & 0.000 & 0.000 & $\mathrm{n} / \mathrm{a}$ & 0.000 & 0.000 & $\mathrm{n} / \mathrm{a}$ \\
\hline $\mathrm{j}=1$ & 3838 & 1776 & 2062 & 1.000 & 1.000 & 0.469 & 0.530 & $\begin{array}{l}-0.061^{* * *} \\
(0.007)\end{array}$ & 0.469 & 0.530 & $\begin{array}{l}-0.061^{* * *} \\
(0.007)\end{array}$ \\
\hline$j=2$ & 2509 & 1061 & 1448 & 1.000 & 1.000 & 0.617 & 0.649 & $\begin{array}{l}-0.032^{* * *} \\
(0.007)\end{array}$ & 0.617 & 0.649 & $\begin{array}{l}-0.032^{* * * *} \\
(0.007)\end{array}$ \\
\hline$j=3$ & 1067 & 397 & 670 & 1.000 & 1.000 & 0.812 & 0.822 & $\begin{array}{l}-0.010 \\
(0.007)\end{array}$ & 0.812 & 0.822 & $\begin{array}{l}-0.010 \\
(0.007)\end{array}$ \\
\hline$j=4$ & 290 & 98 & 192 & 1.000 & 1.000 & 1.000 & 1.000 & $\begin{array}{l}0.000 \\
(0.000)\end{array}$ & 1.000 & 1.000 & $\begin{array}{l}0.000 \\
(0.000)\end{array}$ \\
\hline \multicolumn{12}{|l|}{$\overline{\mathbf{k}}=\mathbf{2}$} \\
\hline $\mathrm{j}=0$ & 314 & 171 & 143 & 1.000 & 1.000 & 0.000 & 0.000 & $\mathrm{n} / \mathrm{a}$ & 0.000 & 0.000 & $\mathrm{n} / \mathrm{a}$ \\
\hline$j=1$ & 2948 & 1247 & 1701 & 1.000 & 1.000 & 0.493 & 0.543 & $\begin{array}{l}-0.050 * * * \\
(0.009)\end{array}$ & 0.493 & 0.543 & $\begin{array}{l}-0.050^{* * *} \\
(0.009)\end{array}$ \\
\hline $\mathrm{j}=2$ & 2035 & 806 & 1229 & 1.000 & 1.000 & 0.626 & 0.656 & $\begin{array}{l}-0.030 * * * \\
(0.008)\end{array}$ & 0.626 & 0.656 & $\begin{array}{l}-0.030 * * * \\
(0.008)\end{array}$ \\
\hline$j=3$ & 916 & 328 & 588 & 1.000 & 1.000 & 0.809 & 0.826 & $\begin{array}{l}-0.017 * \\
(0.008)\end{array}$ & 0.809 & 0.826 & $\begin{array}{l}-0.017 * \\
(0.008)\end{array}$ \\
\hline $\mathrm{j}=4$ & 257 & 78 & 179 & 1.000 & 1.000 & 1.000 & 1.000 & $\begin{array}{l}0.000 \\
(0.000)\end{array}$ & 1.000 & 1.000 & $\begin{array}{l}0.000 \\
(0.000)\end{array}$ \\
\hline$\overline{\mathbf{k}}=\mathbf{3}$ & & & & & & & & & & & \\
\hline $\mathrm{j}=0$ & 153 & 68 & 85 & 1.000 & 1.000 & 0.000 & 0.000 & $\mathrm{n} / \mathrm{a}$ & 0.000 & 0.000 & $\mathrm{n} / \mathrm{a}$ \\
\hline $\mathrm{j}=1$ & 1574 & 573 & 1001 & 1.000 & 1.000 & 0.497 & 0.545 & $\begin{array}{l}-0.048 * * * \\
(0.012)\end{array}$ & 0.497 & 0.545 & $\begin{array}{l}-0.048^{* * * *} \\
(0.012)\end{array}$ \\
\hline $\mathrm{j}=2$ & 1113 & 379 & 734 & 1.000 & 1.000 & 0.623 & 0.653 & $\begin{array}{l}-0.029 * * \\
(0.011)\end{array}$ & 0.623 & 0.653 & $\begin{array}{l}-0.029 * * \\
(0.011)\end{array}$ \\
\hline $\mathrm{j}=3$ & 505 & 157 & 348 & 1.000 & 1.000 & 0.798 & 0.822 & $\begin{array}{l}-0.024^{*} \\
(0.010)\end{array}$ & 0.798 & 0.822 & $\begin{array}{l}-0.024^{*} \\
(0.010)\end{array}$ \\
\hline $\mathrm{j}=4$ & 130 & 30 & 100 & 1.000 & 1.000 & 1.000 & 1.000 & $\begin{array}{l}0.000 \\
(0.000)\end{array}$ & 1.000 & 1.000 & $\begin{array}{l}0.000 \\
(0.000)\end{array}$ \\
\hline $\mathbf{k}=\mathbf{4}$ & & & & & & & & & & & \\
\hline $\mathrm{J}=0$ & 82 & 35 & 47 & 1.000 & 000 & 0.000 & 0.000 & $\mathrm{n} / \mathrm{a}$ & 0.000 & 0.000 & n/a \\
\hline $\mathrm{j}=1$ & 931 & 297 & 634 & 1.000 & 1.000 & 0.513 & 0.560 & $\begin{array}{l}-0.048^{* *} \\
(0.016)\end{array}$ & 0.513 & 0.560 & $\begin{array}{l}-0.048 * * \\
(0.016)\end{array}$ \\
\hline$j=2$ & 678 & 201 & 477 & 1.000 & 1.000 & 0.638 & 0.662 & $\begin{array}{l}-0.024 \\
(0.015)\end{array}$ & 0.638 & 0.662 & $\begin{array}{l}-0.024 \\
(0.015)\end{array}$ \\
\hline $\mathrm{j}=3$ & 332 & 93 & 239 & 1.000 & 1.000 & 0.798 & 0.824 & $\begin{array}{l}-0.026 \\
(0.014)\end{array}$ & 0.798 & 0.824 & $\begin{array}{l}-0.026 \\
(0.014)\end{array}$ \\
\hline $\mathrm{j}=4$ & 89 & 18 & 71 & 1.000 & 1.000 & 1.000 & 1.000 & $\begin{array}{l}0.000 \\
(0.000)\end{array}$ & 1.000 & 1.000 & $\begin{array}{l}0.000 \\
(0.000)\end{array}$ \\
\hline
\end{tabular}

Standard errors in parentheses. Significance levels are denoted as $* * * p<0.01 ; * * p<0.05 ; * p<0.1$ 
Table 4: Calculation of $M^{0}$ Defining Subgroups According to BRAC targeting criteria and Basic Needs Indicators for Evaluation, 2005

\begin{tabular}{|c|c|c|c|c|c|c|c|c|c|c|c|}
\hline \multirow[t]{2}{*}{$\begin{array}{c}\text { Year } \\
\text { (a) } \\
2005\end{array}$} & \multicolumn{3}{|c|}{ Number of obs } & \multicolumn{2}{|c|}{$\begin{array}{l}\text { Headcount } \\
\text { Ratio } \\
\text { (c) }\end{array}$} & \multicolumn{3}{|c|}{$\begin{array}{c}\text { Average share } \\
\text { of Deprivations } \\
\text { (d) }\end{array}$} & \multicolumn{3}{|c|}{$\begin{array}{c}M^{0} \text { Indicator } \\
=H \times A \\
(\mathrm{e})\end{array}$} \\
\hline & $\mathrm{N}$ & Control & Treated & Control & Treated & Control & Treated & Difference & Control & Treated & Difference \\
\hline \multicolumn{12}{|l|}{$k=1$} \\
\hline $\mathrm{j}=0$ & 886 & 318 & 568 & 1.085 & 3.070 & 0.000 & 0.000 & $\mathrm{n} / \mathrm{a}$ & 0.000 & 0.000 & $\mathrm{n} / \mathrm{a}$ \\
\hline $\mathrm{j}=1$ & 3430 & 1751 & 1679 & 0.986 & 0.814 & 0.451 & 0.408 & $\begin{array}{l}0.042^{* * *} \\
(0.007)\end{array}$ & 0.444 & 0.332 & $\begin{array}{l}0.112^{* * *} \\
(0.006)\end{array}$ \\
\hline$j=2$ & 1855 & 1026 & 829 & 0.967 & 0.573 & 0.593 & 0.571 & $\begin{array}{l}0.022^{* * * *} \\
(0.006)\end{array}$ & 0.573 & 0.327 & $\begin{array}{l}0.246^{* * *} \\
(0.005)\end{array}$ \\
\hline$j=3$ & 540 & 332 & 208 & 0.836 & 0.310 & 0.786 & 0.781 & $\begin{array}{l}0.005 \\
(0.008)\end{array}$ & 0.657 & 0.243 & $\begin{array}{l}0.415^{* * *} \\
(0.005)\end{array}$ \\
\hline $\mathrm{j}=4$ & 74 & 48 & 26 & 0.490 & 0.135 & 1.000 & 1.000 & $\begin{array}{l}0.000 \\
(0.000)\end{array}$ & 0.490 & 0.135 & $\begin{array}{l}0.354 \\
(0.000)\end{array}$ \\
\hline \multicolumn{12}{|l|}{$\overline{\mathbf{k}}=\mathbf{2}$} \\
\hline $\mathrm{j}=0$ & 615 & 186 & 429 & 1.088 & 3.000 & 0.000 & 0.000 & $\mathrm{n} / \mathrm{a}$ & 0.000 & 0.000 & $\mathrm{n} / \mathrm{a}$ \\
\hline$j=1$ & 2647 & 1232 & 1415 & 0.988 & 0.832 & 0.469 & 0.411 & $\begin{array}{l}0.059 * * * \\
(0.008)\end{array}$ & 0.464 & 0.342 & $\begin{array}{l}0.122 * * * \\
(0.007)\end{array}$ \\
\hline$j=2$ & 1473 & 767 & 706 & 0.952 & 0.574 & 0.602 & 0.572 & $\begin{array}{l}0.030 * * * \\
(0.007)\end{array}$ & 0.573 & 0.329 & $\begin{array}{l}0.244^{* * * *} \\
(0.006)\end{array}$ \\
\hline$j=3$ & 456 & 275 & 181 & 0.838 & 0.308 & 0.785 & 0.782 & $\begin{array}{l}0.004 \\
(0.008)\end{array}$ & 0.659 & 0.241 & $\begin{array}{l}0.418^{* * *} \\
(0.006)\end{array}$ \\
\hline $\mathrm{j}=4$ & 62 & 39 & 23 & 0.500 & 0.128 & 1.000 & 1.000 & $\begin{array}{l}0.000 \\
(0.000)\end{array}$ & 0.500 & 0.128 & $\begin{array}{l}0.372 \\
(0.000)\end{array}$ \\
\hline$\overline{\mathbf{k}}=\overline{3}$ & & 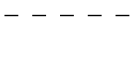 & & & -- & & -- & & & & \\
\hline$j=0$ & 310 & 84 & 226 & 1.235 & 2.659 & 0.000 & 0.000 & $\mathrm{n} / \mathrm{a}$ & 0.000 & 0.000 & $\mathrm{n} / \mathrm{a}$ \\
\hline$j=1$ & 1417 & 557 & 860 & 0.972 & 0.859 & 0.480 & 0.412 & $\begin{array}{l}0.068 * * * \\
(0.011)\end{array}$ & 0.466 & 0.354 & $\begin{array}{l}0.112^{* * *} \\
(0.010)\end{array}$ \\
\hline$j=2$ & 799 & 367 & 432 & 0.968 & 0.589 & 0.599 & 0.573 & $\begin{array}{l}0.026^{* *} \\
(0.010)\end{array}$ & 0.580 & 0.337 & $\begin{array}{l}0.243^{* * *} \\
(0.008)\end{array}$ \\
\hline $\mathrm{j}=3$ & 236 & 123 & 113 & 0.783 & 0.325 & 0.795 & 0.779 & $\begin{array}{l}0.016 \\
(0.012)\end{array}$ & 0.623 & 0.253 & $\begin{array}{l}0.370^{* * * *} \\
(0.007)\end{array}$ \\
\hline $\begin{array}{c}\mathrm{j}=4 \\
\overline{\mathbf{k}}=\mathbf{4}\end{array}$ & 35 & 22 & 13 & 0.733 & $\begin{array}{l}0.130 \\
----\end{array}$ & 1.000 & $\begin{array}{l}1.000 \\
----\end{array}$ & $\begin{array}{l}0.000 \\
(0.000) \\
-----\end{array}$ & 0.733 & 0.130 & $\begin{array}{l}0.603 \\
(0.000)\end{array}$ \\
\hline$j=0$ & 177 & 44 & 133 & 1.257 & 2.830 & 0.000 & 0.000 & $\mathrm{n} / \mathrm{a}$ & 0.000 & 0.000 & $\mathrm{n} / \mathrm{a}$ \\
\hline $\mathrm{j}=1$ & 836 & 288 & 548 & 0.970 & 0.864 & 0.487 & 0.412 & $\begin{array}{l}0.075^{* * *} \\
(0.014)\end{array}$ & 0.472 & 0.356 & $\begin{array}{l}0.116^{* * *} \\
(0.013)\end{array}$ \\
\hline $\mathrm{j}=2$ & 470 & 192 & 278 & 0.955 & 0.583 & 0.605 & 0.570 & $\begin{array}{l}0.035 * * \\
(0.013)\end{array}$ & 0.578 & 0.332 & $\begin{array}{l}0.246^{* * * *} \\
(0.010)\end{array}$ \\
\hline $\mathrm{j}=3$ & 138 & 67 & 71 & 0.720 & 0.297 & 0.802 & 0.775 & $\begin{array}{l}0.028 \\
(0.015)\end{array}$ & 0.578 & 0.230 & $\begin{array}{l}0.348^{* * *} \\
(0.009)\end{array}$ \\
\hline$j=4$ & 21 & 14 & 7 & 0.778 & 0.099 & 1.000 & 1.000 & $\begin{array}{l}0.000 \\
(0.000)\end{array}$ & 0.778 & 0.099 & $\begin{array}{l}0.679 \\
(0.000)\end{array}$ \\
\hline
\end{tabular}

Standard errors in parentheses. Significance levels are denoted as $* * * p<0.01 ; * * p<0.05 ; * p<0.1$ 
Table 5: Difference-in-Difference in M0 Indicator based on initial targeting criteria $k$

\begin{tabular}{|c|c|c|c|c|}
\hline & $\begin{array}{l}\mathrm{k}=1 \\
(1)\end{array}$ & $\begin{array}{l}\mathrm{k}=2 \\
(2)\end{array}$ & $\begin{array}{l}\mathrm{k}=3 \\
(3)\end{array}$ & $\begin{array}{c}\mathrm{k}=4 \\
(4)\end{array}$ \\
\hline DID & $\begin{array}{c}-0.093^{* * *} \\
(0.005)\end{array}$ & $\begin{array}{c}-0.198^{* * *} \\
(0.007)\end{array}$ & $\begin{array}{c}-0.258^{* * *} \\
(0.008)\end{array}$ & $\begin{array}{c}-0.577 * * * \\
(0.011)\end{array}$ \\
\hline 95\% C.I. & {$[-0.102,-0.083]$} & {$[-0.211,-0.185]$} & {$[-0.274,-0.242]$} & {$[-0.598,-0.556]$} \\
\hline Constant & $\begin{array}{c}-0.059^{* * * *} \\
(0.008)\end{array}$ & $\begin{array}{c}-0.035^{* * * *} \\
(0.010)\end{array}$ & $\begin{array}{l}-0.026 \\
(0.026)\end{array}$ & $\begin{array}{c}-0.050^{* * * *} \\
(0.007)\end{array}$ \\
\hline Ōbservations & $\overline{4}, \overline{0} \overline{2} 8-$ & $\overline{2}, \overline{1} \overline{7} \overline{1}$ & $\overline{1,300}$ & $\overline{3} \overline{2} \overline{1}$ \\
\hline $\mathrm{R}$-squared & 0.122 & 0.437 & 0.465 & 0.923 \\
\hline
\end{tabular}

Notes: (1) Robust standard errors in parentheses. Significance levels are denoted as $* * * p<0.01 ; * * p<0.05 ; * p<0.1$ (2) Controls included are: household size, female working as a day-laborer, land ownership (dummy) and sex of household head. 
Table 7: Difference-in-Difference in M0 Indicator according to basic needs indicators $j$

\begin{tabular}{|c|c|c|c|c|c|}
\hline & (1) & (2) & (3) & (4) & (5) \\
\hline & $j=0$ & $j=1$ & $j=2$ & $j=3$ & $j=4$ \\
\hline \multirow[t]{2}{*}{ DID } & $1.985^{* * *}$ & $-0.185^{* * *}$ & $-0.300 * * *$ & $-0.435^{* * *}$ & $-0.354 * * *$ \\
\hline & $(0.000)$ & $(0.010)$ & $(0.012)$ & $(0.017)$ & $(0.000)$ \\
\hline $95 \%$ C.I. & {$[1.985,1.985]$} & {$[-0.204,-0.166]$} & {$[-0.324,-0.277]$} & {$[-0.467,-0.402]$} & {$[-0.354,-0.354]$} \\
\hline \multirow[t]{2}{*}{ Constant } & $0.085^{* * *}$ & $-0.040 * *$ & $-0.085 * * *$ & $-0.231^{* * *}$ & $-0.510 * * *$ \\
\hline & $(0.000)$ & $(0.016)$ & $(0.020)$ & $(0.031)$ & $(0.000)$ \\
\hline Ōbservations & $\overline{1} \overline{4} 3^{-}$ & $\overline{2} \overline{9} \overline{9} \overline{6}$ & $\overline{1,23 \overline{8}}$ & $\overline{2} 32^{-}$ & 14 \\
\hline $\mathrm{R}$-squared & 1.000 & 0.118 & 0.344 & 0.746 & 1.000 \\
\hline
\end{tabular}

Note: Robust standard errors in parentheses. Significance levels are denoted as $* * * p<0.01 ; * * p<0.05 ; * p<0.1$

Total N=3264; all individuals in BRAC's set of potential participants with initially at least one inclusion criterion. Controls included are: household size, female working as a day-laborer, land ownership (dummy) and sex of household head. 


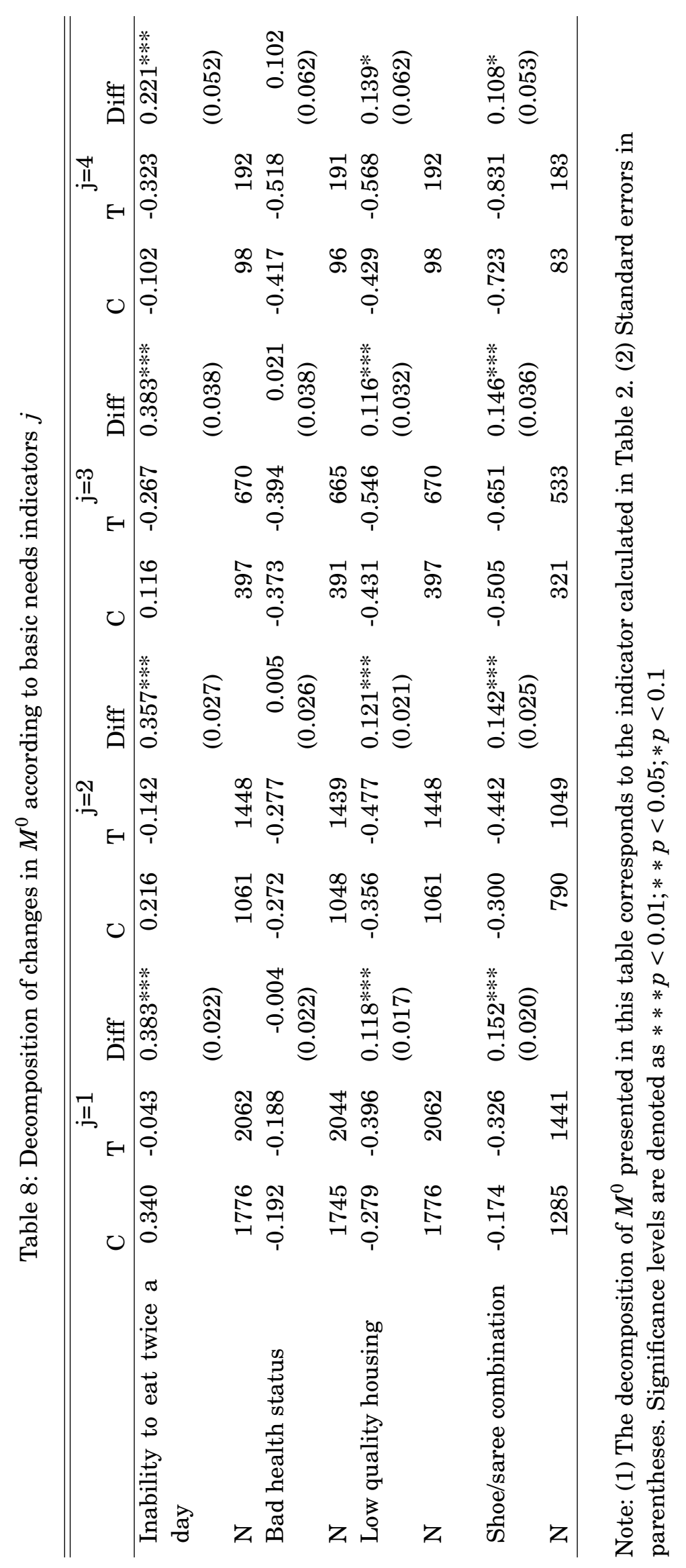


Table 9: Difference-in-Difference in integrated M0 Indicator according to initial targeting criteria $k$ and basic needs indicators $j$

\begin{tabular}{|c|c|c|c|c|}
\hline & (1) & (2) & $\overline{(3)}$ & $\overline{(4)}$ \\
\hline & $j=1$ & $j=2$ & $j=3$ & $\mathrm{j}=4$ \\
\hline $\mathrm{k}=1$ & $-0.185^{* * *}$ & $-0.300 * * *$ & $-0.435^{* * *}$ & $-0.354^{* * *}$ \\
\hline & $(0.010)$ & $(0.012)$ & $(0.017)$ & $(0.000)$ \\
\hline 95\% C.I. & {$[-0.204,-0.166]$} & {$[-0.324,-0.277]$} & {$[-0.467,-0.402]$} & {$[-0.354,-0.354]$} \\
\hline Observations & 2,996 & 1,238 & 232 & 14 \\
\hline $\mathrm{k}=2$ & $\begin{array}{c}-0.185^{* * *} \\
(0.011)\end{array}$ & $\begin{array}{c}-0.296^{* * *} \\
(0.013)\end{array}$ & $\begin{array}{c}-0.440 * * * \\
(0.018)\end{array}$ & $\begin{array}{c}-0.372^{* * *} \\
(0.000)\end{array}$ \\
\hline 95\% C.I. & {$[-0.207,-0.163]$} & {$[-0.322,-0.271]$} & {$[-0.475,-0.405]$} & {$[-0.372,-0.372]$} \\
\hline Observations & 2,342 & 1,035 & 212 & 11 \\
\hline $\mathrm{k}=3$ & $\begin{array}{c}-0.166^{* * *} \\
(0.015)\end{array}$ & $\begin{array}{c}-0.301^{* * *} \\
(0.018)\end{array}$ & $\begin{array}{c}-0.406^{* * * *} \\
(0.024)\end{array}$ & $\begin{array}{c}-0.603^{* * *} \\
(0.000)\end{array}$ \\
\hline 95\% C.I. & {$[-0.196,-0.136]$} & {$[-0.336,-0.266]$} & {$[-0.453,-0.358]$} & {$[-0.603,-0.603]$} \\
\hline Observations & $\underline{1,261}$ & 569 & 110 & 7 \\
\hline $\mathrm{k}=4$ & $\begin{array}{c}-0.165^{* * *} \\
(0.020)\end{array}$ & $\begin{array}{c}-0.304^{* * *} \\
(0.023)\end{array}$ & $\begin{array}{c}-0.368^{* * * *} \\
(0.031)\end{array}$ & $\begin{array}{l}-0.679 \\
(0.000)\end{array}$ \\
\hline $95 \%$ C.I. & {$[-0.204,-0.126]$} & {$[-0.349,-0.259]$} & {$[-0.429,-0.307]$} & . \\
\hline Observations & 763 & 346 & 75 & 3 \\
\hline
\end{tabular}

Robust standard errors in parentheses. Significance levels are denoted as $* * * p<0.01 ; * * p<0.05 ; * p<0.1$. Controls included are: household size, female working as a day-laborer, land ownership (dummy) and sex of household head. 


\section{A Appendix Tables}

Table A.1: Summary statistics

\begin{tabular}{|c|c|c|c|c|}
\hline & Year & Mean & Std. Dev. & Obs \\
\hline \multirow[t]{2}{*}{ Own homestead land (dummy) } & 2002 & 0.54 & 0.50 & 5067 \\
\hline & 2005 & 0.53 & 0.50 & 5067 \\
\hline \multirow[t]{2}{*}{ Total amount of land owned } & 2002 & 4.30 & 14.57 & 5067 \\
\hline & 2005 & 4.36 & 15.11 & 5067 \\
\hline \multirow[t]{2}{*}{ Roof made of tin (dummy) } & 2002 & 0.50 & 0.50 & 5067 \\
\hline & 2005 & 0.78 & 0.41 & 5067 \\
\hline \multirow[t]{2}{*}{ Number of cows/bulls } & 2002 & 0.11 & 0.51 & 5067 \\
\hline & 2005 & 0.94 & 1.21 & 5067 \\
\hline \multirow[t]{2}{*}{ Number of goats/sheep } & 2002 & 0.11 & 0.49 & 5067 \\
\hline & 2005 & 0.34 & 0.97 & 5067 \\
\hline \multirow[t]{2}{*}{ Number of ducks/hens } & 2002 & 1.15 & 2.83 & 5067 \\
\hline & 2005 & 2.53 & 3.69 & 5067 \\
\hline \multirow[t]{2}{*}{ Number of fishing nets } & 2002 & 0.00 & 0.05 & 5067 \\
\hline & 2005 & 0.15 & 0.60 & 5067 \\
\hline \multirow[t]{2}{*}{ Number of big trees } & 2002 & 0.89 & 5.97 & 5067 \\
\hline & 2005 & 0.61 & 2.76 & 5067 \\
\hline \multirow[t]{2}{*}{ Number of rickshaw/vans } & 2002 & 0.03 & 0.27 & 5067 \\
\hline & 2005 & 0.07 & 0.28 & 5067 \\
\hline \multirow[t]{2}{*}{ Number of bicycles } & 2002 & 0.01 & 0.08 & 5067 \\
\hline & 2005 & 0.02 & 0.15 & 5067 \\
\hline \multirow[t]{2}{*}{ Number of chair/tables } & 2002 & 0.37 & 0.80 & 5067 \\
\hline & 2005 & 0.65 & 1.05 & 5067 \\
\hline \multirow[t]{2}{*}{ Number of beds } & 2002 & 0.88 & 0.73 & 5067 \\
\hline & 2005 & 1.14 & 0.76 & 5067 \\
\hline \multirow[t]{2}{*}{ Number of radio/TVs } & 2002 & 0.01 & 0.12 & 5067 \\
\hline & 2005 & 0.03 & 0.18 & 5067 \\
\hline \multirow[t]{2}{*}{ Number of quilt/blankets } & 2002 & 0.03 & 0.21 & 5067 \\
\hline & 2005 & 0.16 & 0.44 & 5067 \\
\hline \multirow[t]{2}{*}{ Number of tubewells } & 2002 & 0.03 & 0.16 & 5067 \\
\hline & 2005 & 0.45 & 0.50 & 5067 \\
\hline
\end{tabular}


Table A.2: Summary statistics, cont.

\begin{tabular}{rrrrr}
\hline \hline & Year & Mean & Std. Dev. & Obs \\
\hline Food availability & 2002 & 1.55 & 0.63 & 5067 \\
& 2005 & 2.06 & 0.78 & 5067 \\
Number of sarees & 2002 & 1.81 & 0.59 & 5067 \\
& 2005 & 2.21 & 0.82 & 5067 \\
Shoes (dummy) & 2002 & 0.62 & 0.48 & 5067 \\
& 2005 & 0.90 & 0.30 & 5067 \\
Health status & 2002 & 2.32 & 0.97 & 5055 \\
& 2005 & 2.50 & 1.07 & 5013 \\
Health improvement & 2002 & 2.61 & 1.10 & 5055 \\
& 2005 & 2.93 & 1.06 & 5013 \\
Presence of girl labor (dummy) & 2002 & 0.07 & 0.26 & 5067 \\
& 2005 & 0.11 & 0.32 & 5067 \\
Ybility of girls to read and write (dummy) & 2002 & 0.08 & 0.27 & 5067 \\
& 2005 & 0.07 & 0.26 & 5067 \\
Years of schooling of girls & 2002 & 0.35 & 0.48 & 5067 \\
& 2005 & 0.23 & 0.42 & 5067 \\
Presence of child labor (dummy) & 2002 & 0.15 & 0.35 & 5067 \\
& 2005 & 0.19 & 0.39 & 5067 \\
\hline
\end{tabular}


Table A.3: Incidence of Exclusion and Inclusion Criteria, 2002

\begin{tabular}{lrrl}
\hline \hline & (a) Description of Exclusion Criteria & N & $\begin{array}{l}\text { Headcount } \\
\text { Ratio }\end{array}$ \\
\hline EC1 & Participant in another NGO & 444 & 0.09 \\
EC2 & Recipient of a VGD card & 127 & 0.03 \\
EC3 & No healthy female at home able to work for the program & 48 & 0.01 \\
& Full Sample & $\mathbf{5 0 6 7}$ & $\mathbf{1 . 0 0}$ \\
\hline & (b) Description of Inclusion Criteria & $\mathbf{N}$ & Headcount \\
& & & Ratio \\
\hline IC1 & Owns less than ten decimals of land & 4624 & 0.91 \\
IC2 & No male income earner at home & 1893 & 0.37 \\
IC3 & Presence of child labor & 740 & 0.15 \\
IC4 & Female having to work outside household & 1627 & 0.32 \\
IC5 & No productive assets & 2791 & 0.55 \\
& Full sample & $\mathbf{5 0 6 7}$ & $\mathbf{1 . 0 0}$ \\
\hline
\end{tabular}

Notes: (1) BRAC established that if the household met any of the three previous conditions, they should not be selected for participating into the CFPR/TUP I program, because the specific purpose of the latter was to focus on household who were overlooked by previous programs (because of their extreme poverty condition or for some other characteristic that would prevent them from fully benefiting). The first two exclusion criteria aim at "excluding-up" households: if they meet any of the two conditions they should not be qualified as ultra-poor. The last criterion focus on "excluding-down" households, that is, if there is no healthy female able to work from the program, there is no point in them participating; another solution has to be found for them. (2) The Headcount Ratio indicates the prevalence of the characteristic across the full sample of households. (3) The households identified by the exclusion criterion comprise part of the type- 2 errors in assignment (selecting ineligible participants). (4) To be classified as Ultra-Poor, households had to meet at least three of the five Inclusion Criteria described in panel (b) above, but 202 households in the sample to not meet any of the Inclusion Criteria. 
Table A.4: Number of deprivation criteria met by selected households despite disqualification by the Exclusion Criteria

\begin{tabular}{|c|c|c|c|c|}
\hline & EC1 & $\overline{\mathrm{EC} 2}$ & EC3 & Total \\
\hline Satisfy all 5 criteria of inclusion & 3 & 0 & 2 & 5 \\
\hline Satisfy 4 (any) criteria of inclusion & 11 & 12 & 12 & 35 \\
\hline Satisfy 3 (any) criteria of inclusion & 14 & 9 & 6 & 29 \\
\hline Satisfy 2 (any) criteria of inclusion & 14 & 9 & 1 & 24 \\
\hline Satisfy 1 (any) criteria of inclusion & 6 & 5 & 1 & 12 \\
\hline Satisfy no criterion & 1 & 0 & 0 & 1 \\
\hline Total treated $\overline{(\mathrm{t})}$ & 49 & 35 & 22 & $1 \overline{0} \overline{6}$ \\
\hline Total $(\mathrm{N})$ & 444 & 127 & 48 & 619 \\
\hline proportion $(\mathrm{t} / \mathrm{N})$ & 0.11 & 0.28 & 0.46 & 0.17 \\
\hline
\end{tabular}

Note: This table indicates for the year 2002 who were the households selected for program participation that met the exclusion criteria (and therefore should have been rejected as participants). The rows indicate how many of the inclusion criteria the households met. Additionally, there was one household who met the EC1 and did not meet any of the inclusion criteria but was selected for program participation. The second-to-last row indicates how many of the households met each exclusion criterion. Recall that (EC1) participating in another NGO; (EC2) were recipient of a VGD food card; (EC3) there was no female able to work.

Table A.5: Derivation of M0 Indicator for the original BRAC sample

\begin{tabular}{|c|c|c|c|c|c|c|c|c|c|c|c|}
\hline $\begin{array}{c}\text { Year } \\
\text { (a) }\end{array}$ & & amber o & obs & $\begin{array}{r}\text { Head } \\
\text { Ra } \\
(c\end{array}$ & $\begin{array}{l}\text { count } \\
\text { tio } \\
\text { c) }\end{array}$ & & $\begin{array}{r}\text { verage } s \\
\text { Depriv } \\
\text { (d) }\end{array}$ & $\begin{array}{l}\text { tare } \\
\text { tions }\end{array}$ & & $\begin{array}{c}\bar{M}^{0} \text { Indic } \\
=H \times \\
\text { (e) }\end{array}$ & tor \\
\hline 2002 & $\mathrm{~N}$ & Control & Treated & Control & Treated & Control & Treated & Difference & Control & Treated & Difference \\
\hline SUP / & 5067 & 2692 & 2375 & 1.000 & 1.000 & 0.403 & 0.526 & $-0.123 * * *$ & 0.403 & 0.526 & $-0.123 * * *$ \\
\hline NSUP & & & & & & & & $(0.007)$ & & & $(0.007)$ \\
\hline $\mathrm{EC}$ & 597 & 494 & 103 & 1.000 & 1.000 & 0.375 & 0.584 & $\begin{array}{l}-0.209 * * * \\
(0.027)\end{array}$ & 0.375 & 0.584 & -0.209 \\
\hline $\mathrm{IC}=0$ & 154 & 129 & 25 & 1.000 & 1.000 & 0.000 & 0.000 & $\begin{array}{l}0.000 \\
(0.000)\end{array}$ & 0.000 & 0.000 & 0.000 \\
\hline 2005 & $\mathrm{~N}$ & Control & Treated & Control & Treated & Control & Treated & Difference & Control & Treated & Difference \\
\hline $\begin{array}{l}\text { SUP / } \\
\text { NSUP }\end{array}$ & 5067 & 2692 & 2375 & 1.000 & 1.000 & 0.395 & 0.403 & $\begin{array}{l}\mathbf{- 0 . 0 0 8} \\
(0.006)\end{array}$ & 0.395 & 0.403 & $\begin{array}{l}-\mathbf{- 0 . 0 0 8} \\
(0.006)\end{array}$ \\
\hline $\mathrm{EC}$ & 597 & 494 & 103 & 1.000 & 1.000 & 0.390 & 0.482 & $\begin{array}{l}-0.092 * * * \\
(0.024)\end{array}$ & 0.390 & 0.482 & -0.092 \\
\hline $\mathrm{IC}=0$ & 154 & 129 & 25 & 1.000 & 1.000 & 0.153 & 0.112 & $\begin{array}{l}0.041 \\
(0.032)\end{array}$ & 0.153 & 0.112 & 0.041 \\
\hline
\end{tabular}

Notes: (1) SUP/NSUP is the original BRAC classification into treatment (SUP) and control (NSUP) groups. (2) EC is the subgroup of those satisfying at least one exclusion criterion. (3) $\mathrm{IC}=0$ is the subgroup of those without deprivations at the start of the program. (3) Standard errors in parentheses. Significance levels are denoted as $* * * p<0.01 ; * * p<0.05 ; * p<0.1$. 
Table A.6: Difference-in-Difference in M0 Indicator for the original BRAC sample

\begin{tabular}{lccc}
\hline \hline & SUP & EC=0 & IC=0 \\
& $(1)$ & $(2)$ & $(3)$ \\
\hline DID & $-0.106^{* * *}$ & $-0.094^{* * *}$ & -0.054 \\
& $(0.005)$ & $(0.019)$ & $(0.034)$ \\
95\% C.I. & -0.116 & -0.131 & -0.120 \\
& $(-0.097)$ & $(-0.057)$ & $(0.013)$ \\
Constant & $-0.046^{* * *}$ & -0.040 & $0.134^{* * *}$ \\
& $(0.008)$ & $(0.027)$ & $(0.038)$ \\
$-\bar{O} \overline{\text { Observations }}-\overline{-}-\overline{-}-\overline{8} \overline{5} \overline{4}$ & $-\overline{559}$ & - \\
R-squared & 0.123 & 0.113 & 0.076 \\
\hline
\end{tabular}

Robust standard errors in parentheses. Significance levels are denoted as $* * * p<0.01 ; * * p<0.05 ; * p<0.1$ 
Table A.7: Number of Households selected by each (combination of) poverty indicator(s), 2002

\begin{tabular}{|c|c|c|c|c|c|c|}
\hline & \multirow[b]{2}{*}{ Block } & \multirow[b]{2}{*}{ Criteria } & \multirow[b]{2}{*}{ SUP (T) } & \multirow[b]{2}{*}{ NSUP (C) } & \multicolumn{2}{|c|}{ Headcount } \\
\hline & & & & & $\mathrm{N}$ & Ratio \\
\hline BRAC's classification & (1) & SUP/NSUP & 2375 & 2692 & 5067 & \\
\hline \multirow{2}{*}{\multicolumn{7}{|c|}{ 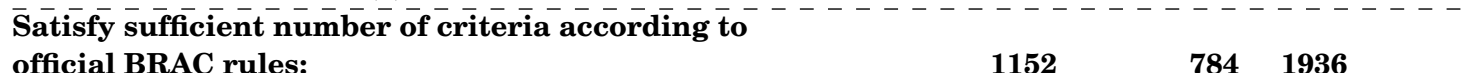 }} \\
\hline & & & 1152 & 784 & 1936 & \\
\hline $\begin{array}{l}\text { Satisfy all five inclu- } \\
\text { sion criteria }\end{array}$ & (2) & $\mathrm{IC} 1 \cup \mathrm{IC} 2 \cup \mathrm{IC} 3 \cup \mathrm{IC} 4 \cup \mathrm{IC} 5$ & 96 & 47 & 143 & 0.03 \\
\hline \multirow[t]{5}{*}{ Satisfy four criteria } & (3) & $\mathrm{IC} 1 \cup \mathrm{IC} 2 \cup \mathrm{IC} 3 \cup \mathrm{IC} 4$ & 63 & 49 & 112 & 0.02 \\
\hline & & $\mathrm{IC} 1 \cup \mathrm{IC} 2 \cup \mathrm{IC} 3 \cup \mathrm{IC} 5$ & 7 & 15 & 22 & 0.00 \\
\hline & & $\mathrm{IC} 1 \cup \mathrm{IC} 2 \cup \mathrm{IC} 4 \cup \mathrm{IC} 5$ & 547 & 287 & 834 & 0.16 \\
\hline & & $\mathrm{IC} 1 \cup \mathrm{IC} 3 \cup \mathrm{IC} 4 \cup \mathrm{IC} 5$ & 1 & 0 & 1 & 0.00 \\
\hline & & $\mathrm{IC} 2 \cup \mathrm{IC} 3 \cup \mathrm{IC} 4 \cup \mathrm{IC} 5$ & 5 & 2 & 7 & 0.00 \\
\hline \multirow[t]{10}{*}{ Satisfy three criteria } & (4) & $\mathrm{IC} 1 \cup \mathrm{IC} 2 \cup \mathrm{IC} 3$ & 7 & 10 & 17 & 0.00 \\
\hline & & $\mathrm{IC} 1 \cup \mathrm{IC} 2 \cup \mathrm{IC} 4$ & 252 & 195 & 447 & 0.09 \\
\hline & & $\mathrm{IC} 1 \cup \mathrm{IC} 2 \cup \mathrm{IC} 5$ & 46 & 63 & 109 & 0.02 \\
\hline & & $\mathrm{IC} 1 \cup \mathrm{IC} 3 \cup \mathrm{IC} 4$ & 0 & 0 & 0 & 0.00 \\
\hline & & $\mathrm{IC} 1 \cup \mathrm{IC} 3 \cup \mathrm{IC} 5$ & 114 & 92 & 206 & 0.04 \\
\hline & & $\mathrm{IC} 1 \cup \mathrm{IC} 4 \cup \mathrm{IC} 5$ & 0 & 1 & 1 & 0.00 \\
\hline & & $\mathrm{IC} 2 \cup \mathrm{IC} 3 \cup \mathrm{IC} 4$ & 3 & 8 & 11 & 0.00 \\
\hline & & IC $2 \cup \mathrm{IC} 3 \cup \mathrm{IC} 5$ & 0 & 1 & 1 & 0.00 \\
\hline & & $\mathrm{IC} 2 \cup \mathrm{IC} 4 \cup \mathrm{IC} 5$ & 11 & 14 & 25 & 0.00 \\
\hline & & IC3 $\cup$ IC4 $\cup$ IC5 & 0 & 0 & 0 & 0.00 \\
\hline \multicolumn{7}{|c|}{$\begin{array}{l}\text { Satisfy insufficient number of criteria according to } \\
\text { official BRAC rules: }\end{array}$} \\
\hline \multirow[t]{10}{*}{ Satisfy two criteria } & (5) & $\mathrm{IC} 1 \cup \mathrm{IC} 2$ & 25 & 54 & 79 & 0.02 \\
\hline & & $\mathrm{IC} 1 \cup \mathrm{IC} 3$ & 69 & 114 & 183 & 0.04 \\
\hline & & $\mathrm{IC} 1 \cup \mathrm{IC} 4$ & 0 & 0 & 0 & 0.00 \\
\hline & & $\mathrm{IC} 1 \cup \mathrm{IC} 5$ & 668 & 675 & 1343 & 0.27 \\
\hline & & $\mathrm{IC} 2 \cup \mathrm{IC} 3$ & 0 & 1 & 1 & 0.00 \\
\hline & & $\mathrm{IC} 2 \cup \mathrm{IC} 4$ & 16 & 30 & 46 & 0.01 \\
\hline & & IC2 $\cup$ IC5 & 1 & 14 & 15 & 0.00 \\
\hline & & $\mathrm{IC} 3 \cup \mathrm{IC} 4$ & 0 & 0 & 0 & 0.00 \\
\hline & & IC3 $\cup$ IC5 & 3 & 6 & 9 & 0.00 \\
\hline & & $\mathrm{IC} 4 \cup \mathrm{IC} 5$ & 0 & 0 & 0 & 0.00 \\
\hline \multirow[t]{5}{*}{ Satisfy one criterion } & (6) & IC1 & 384 & 743 & 1127 & 0.22 \\
\hline & & IC2 & 6 & 18 & 24 & 0.00 \\
\hline & & IC3 & 4 & 23 & 27 & 0.01 \\
\hline & & IC4 & 0 & 0 & 0 & 0.00 \\
\hline & & IC5 & 21 & 54 & 75 & 0.01 \\
\hline $\begin{array}{l}\text { Do not meet any crite- } \\
\text { rion }\end{array}$ & (7) & no criterion & 26 & 176 & 202 & 0.04 \\
\hline
\end{tabular}

Notes: (a) Block (1) presents BRAC's criteria of selection into SUP/NSUP groups.

(b) IC stands for 'Inclusion Criterion'.

Blocks (2) to (6) present the disaggregation of BRAC's criteria according to which and how many of the inclusion criteria are met. In this table they are also included the 106 households that met the initial exclusion restriction. If those 106 households were excluded, the sum of blocks (2), (3) and (4) would give the SB1/SB0 classification used in chapter 2.

The eligibility criteria are: (IC1) ownership of less than 10 decimals of land, (IC2) no male income earner at home, (IC3) children of school age having to work, (IC4) household dependent upon female domestic work outside the household, and (IC5) households having no productive assets.

Block (7) presents the number of households in the SUP/NSUP group that are selected despite not meeting any of the inclusion criteria. 